\title{
WestVirginiaUniversity.
}

Department of Economics

Working Paper Series

\section{The Effect of Urban}

Empowerment Zones on

Fertility and Health: A Case

Study of Chicago, New York

City, and Philadelphia

Daniel Grossman

Working Paper No. 15-44

This paper can be found at the College of Business and Economics

Working Paper Series homepage: 


\title{
The Effect of Urban Empowerment Zones on Fertility and Health: A Case Study of Chicago, New York City, and Philadelphia ${ }^{1}$
}

\author{
Daniel Grossman \\ Assistant Professor, Department of Economics \\ West Virginia University, Morgantown, WV 26506-6025 \\ email: Daniel.grossman@mail.wvu.edu.
}

October 2015

\footnotetext{
${ }^{1}$ I am grateful to John Cawley, Don Kenkel and Michael Lovenheim for helpful comments and guidance in this work. I also thank seminar participants at Cornell University, Florida International University, University of Miami, Melbourne Institute, and West Virginia University. I received material support from the Cornell Population Center, Cornell University Human Ecology Alumni Association, and the Cornell Institute of Health Economics, Health Behaviors, and Disparities, without which this research would not be possible. I thank the Pennsylvania, Ohio, and Florida Departments of Health, Colorado Department of Public Health and Environment, Kentucky Cabinet for Health and Family Services, New York City Department of Health and Mental Hygiene, Oregon Public Health Division, and Texas Department of State Health Services for sharing geocoded birth data. I thank Patrick Kline for sharing a list of empowerment zones and application zones and the census tracts contained therein for each. Samuel Kleiner, Brad Humphreys, Richard Patterson, Anna Choi, Ross Milton and Nicholas Tilipman provided additional helpful comments on this work. This study includes data provided by the Ohio Department of Health which should not be considered an endorsement of this study or its conclusions. Additionally, this study and its conclusions do not necessarily represent the view point of any state agency that provided data.
} 


\title{
The Effect of Urban Empowerment Zones on Fertility and Health: A Case Study of Chicago, New York City, and Philadelphia
}

\begin{abstract}
I estimate the health impacts of the Empowerment Zone (EZ) programa federal program that gave sizeable grants and tax breaks to certain high-poverty census tracts in selected cities. Using difference-in-differences methods, I find that the EZ program decreased fertility rates by 11 percent and improved birth outcomes. This increase in infant health was not driven by changes in the composition of births. Synthetic control methods and estimates using an alternate control group support these findings. Recent research on the later-life impacts of low birth weight suggest that the health impacts of this program may have substantial long-term benefits.
\end{abstract}

\section{Introduction}

Poor neonatal health imposes large costs on individuals and society. Despite low birth weight rates of only 8 percent nationally, low birth weight babies incur nearly half of all neonatal hospital costs (Almond et al. 2010, Russell et al. 2007). Additionally, rates of low birth weight differ greatly by race, with non-Hispanic blacks nearly twice as likely as non-Hispanic whites to have a low birth weight baby (Reichman 2005). The costs of low birth weight are not limited to hospital costs: low birth weight is predictive of worse later-life education, labor market, and health outcomes as well (see e.g., Almond and Currie 2011). Therefore, policies that improve low birth weight rates, especially those that affect mothers who are most likely to have low birth weight babies, are important.

In this paper, I explore whether the empowerment zone (EZ) program-a federal stimulus package aimed at improving infrastructure and labor market conditions in low-income, high-poverty urban areas—-had unintended effects on fertility and health. The EZ program offered generous tax credits to businesses both operating in these areas and hiring EZ residents, and granted \$100 million for infrastructure projects. I study EZs because previous research has shown this 
program increased employment and earnings among zone residents (Busso, Gregory, and Kline 2013, Ham et al. 2011), but no prior study has investigated the health effects of this program.

In addition to providing the first analysis of the EZ program on health, which is an important extension of the literature investigating the overall effects of the EZ program, this paper contributes to the growing literature on the effects of the social safety net on birth outcomes. Previous work has demonstrated that income-targeted programs, including the earned income tax credit (Hoynes, Miller, and Simon 2015) and food stamps (Almond, Hoynes, and Schanzenbach 2011), improve low birth weight rates. Where my work differs and provides an additional contribution is that the EZ is a place-based policy, meaning that the program benefits have to be spent within the program's geographic limits or claimed by individuals living within the zone.

I use vital statistics natality data from 1990-2002 which I link for 9 cities and states to create a unique data set. ${ }^{2}$ The data set consists of restricted-access, administrative records with geocoded census tract of residence for mothers. This level of geographic detail is necessary to study the EZ program, as each EZ is composed of mostly contiguous census tracts. In my main specification, I use difference-in-differences models, comparing areas that received round I EZs to areas that applied for but did not receive EZs or received EZs at a later point in time. These control areas all qualified for EZ status under the program guidelines and are a natural comparison for the EZs. Indeed, these are the areas used as control zones in much of the previous EZ literature (Busso, Gregory, and Kline 2013, Hanson 2009, Hanson and Rohlin 2011, 2013, Reynolds and Rohlin 2013).

To account for pre-treatment trends, I also estimate synthetic control models which create a weighted control group matched on pre-treatment trends.

\footnotetext{
${ }^{2}$ I have data from Colorado, Florida, Kentucky, Pennsylvania, Oregon, Ohio, Texas, the City of Chicago, and New York City.
} 
This creates a treatment and control group that follow similar trajectories in the pre-period, thus creating a counterfactual comparison by which to compare any changes that occur in the treatment area following the implementation of the EZ program. To address concerns about whether control areas from different cities differ on trends of unobservable characteristics, I perform difference-indifferences and synthetic control models using an alternate control group composed of areas in the same city as the EZs.

I find a large and statistically significant effect of EZs on fertility rates, birth weight, and low birth weight. Fertility rates decrease by 10 births per 1,000 females of age 15 to 44 in EZs compared to control areas, an 11 percent decrease. Birth weight increases by 26 grams on average in EZs, while low birth weight rates decrease by 0.8 percentage points in EZs compared to control zones, an 8 percent decline. Fertility effects by age suggest that the decreases in fertility do not reflect women delaying pregnancy to a later point in time, but an overall decrease in fertility. Furthermore, I present evidence that the infant health increases were not driven by changes in the composition of births.

These results suggest that policy makers and researchers should consider the health effects of any program that affects income and infrastructure when developing, implementing and evaluating these programs. Ignoring the health effects of these programs underestimates the overall program effect, especially given the importance of birth outcomes on later life labor and health outcomes.

I describe the institutional details of the EZ program in Section 2. Section 3 provides a literature review and discusses potential channels through which the EZ program may affect health. Section 4 discusses the data. Section 5 describes the methods and identification strategy. In Section 6, I present the main findings, heterogeneous treatment effects, and robustness checks. Section 7 concludes.

\section{Background: Empowerment Zones}


In 1993, Congress announced a competitive bidding process for municipalities to apply to become EZs. The application zones were composed of multiple, generally contiguous census tracts chosen by the city. To qualify, all tracts in the zone were required to have poverty rates above 20 percent, with 90 percent of the tracts having poverty rates above 25 percent and 50 percent of the tracts having rates above 35 percent (Government Accountability Office 2010). Only tracts with unemployment rates above 6.3 percent were eligible. The actual average unemployment rates in the initial EZs were over 24 percent. ${ }^{3}$ Eligible applicant zones must have had a total population below 200,000 and below the greater of 50,000 and ten percent of the most populous city in the area. ${ }^{4}$

The EZ program provided large employment tax credits for employers operating in these areas and exemptions from capital gains taxes. Firms operating in EZs were eligible to receive up to a 20 percent federal tax credit on the first $\$ 15,000$ of an employee's wages annually, but only for employees who also lived in the zones. Because these were federal tax credits, the local governments in these areas would still reap the tax benefits of attracting new businesses or preventing businesses from closing (Hanson and Rohlin 2011).

EZs also were eligible to receive tax exempt bonds and up to $\$ 100$ million in Social Service Block Grant (SSBG) funds for "business assistance, infrastructure investment, physical development, training programs, youth services, promotion of home ownership, and emergency housing assistance" (Busso, Gregory, and Kline 2013). ${ }^{5}$ Private funds provided upwards of $\$ 7$ of additional investment for every \$1 of SSBG funds spent in EZs.

In December 1994, Congress authorized the funding of six initial urban EZs: portions of Atlanta, Baltimore, Chicago, Detroit, New York City, and

\footnotetext{
${ }^{3}$ All poverty and unemployment restrictions were based on the 1990 Census.

${ }^{4}$ This was to ensure that the treatment would be large enough to make a difference in the selected area while preventing the money from being spent across an entire city.

${ }^{5}$ The New York EZ also received guarantees of $\$ 100$ million from both the state and the city government for a total of $\$ 300$ million.
} 
Philadelphia/Camden and 60 "Enterprise Communities." Enterprise communities are areas that applied for EZ status but were denied. They were eligible for up to $\$ 3$ million in SSBG funds and tax-exempt bond financing, but were not eligible for business tax credits. If anything, this slight treatment will bias my results towards zero where the enterprise communities are used as a control group.

I present maps of the Chicago, New York, and Philadelphia EZs in Figure 1. These maps show the full city, census tracts that received the EZ program in black, and tracts that did not receive the program, but had poverty rates above 20 percent in gray. These areas were not include in the city EZ application, but had poverty rates that made them eligible for the program.

By the year 2000, over $\$ 400$ million dollars in block grant funds had been spent in EZs and over \$200 million in tax credits had been claimed. Tax credit claims grew each year between 1994 and 2000 with over $\$ 55$ million claimed in 2000 alone (Busso, Gregory, and Kline 2013).

\subsection{Previous EZ Literature}

Previous studies examining the EZ program have estimated the effect of the program on wages (Busso, Gregory, and Kline 2013, Oakley and Tsao 2006, Reynolds and Rohlin 2013), employment (Busso, Gregory, and Kline 2013), property values (Hanson 2009), owner-occupied housing (Krupka and Noonan 2009), firm relocation (Hanson and Rohlin 2011), and geographic spillover effects of the program (Hanson and Rohlin 2013). While some find EZs had little impact (Oakley and Tsao 2006), newer work, using restricted employment and administrative data at both the household and establishment level, report large wage and employment effects (Busso, Gregory, and Kline 2013). I extend that literature by estimating impacts of the EZ program on fertility and health.

\subsection{Additional Literature}


EZs may affect infant health through the following channels: fertility, income, local macroeconomic conditions, and infrastructure and neighborhood effects. Below, I discuss these potential mechanisms.

If EZs increase wages and employment, demand for children should increase. ${ }^{6}$ Yet, fertility rates decrease during periods of high unemployment (e.g., Becker 1960, Dehejia and Lleras-Muney 2004). Less-educated, lower earning women are less likely to reproduce in response to better labor market conditions (Perry 2004), implying that for these women, the substitution effect on fertility may be stronger than the income effect (Heckman and Walker 1990). This implies that for high poverty, high unemployment areas, like EZs, there may be a decrease in overall fertility rates. Also, women select into fertility when unemployment rates are high which may affect infant health through compositional changes and behavioral effects ((Dehejia and Lleras-Muney 2004, Aparicio and Gonzalez 2014).

Increases in income affect infant health by raising the demand for health inputs in the birth weight production function leading to health improvements (Corman and Grossman 1985, Currie 2009). Finding plausibly exogenous income shocks that do not affect the outcome of interest can be difficult (Almond and Currie 2011). A recent literature uses changes in the social safety net to study the effect of income on health. Hoynes, Miller, and Simon (2015) find low birth weight rates decrease when earned-income tax credits increase among lesseducated single women. Investigating the effect of the rollout of food stamps on infant health, Almond, Hoynes, and Schanzenbach (2011) find similarly sized decreases in low birth weight rates. Income targeting programs have their own endogeneity issues in that income itself may be endogenous. Thus, evaluating the health effects of place-based programs provides an additional data point by which

${ }^{6}$ This assumes children are normal goods (see e.g. Black et al. 2013, Lovenheim and Mumford 2013, Lindo 2010) 
to evaluate the effect of income on health and fertility.

Income shocks also can affect child health through expenditures on market goods. Investigating the effect of a partner's job loss on birth outcomes, Lindo (2011) finds large decreases in birth weight, especially among the lower half of the birth weight distribution, with suggestive evidence that individuals may reduce food expenditures after a job separation. Coupled with evidence that EZs draw new businesses to the areas (Hanson and Rohlin 2011), this suggests that newly hired individuals may increase food expenditures when pregnant and have a lower opportunity cost of shopping which may affect birth outcomes.

However, the macroeconomy and health literature suggests a potential negative effect of improved labor markets on birth outcomes. During periods of high unemployment, pregnant individuals reduce drinking and smoking, are more likely to exercise, have better sleep habits, and receive improved prenatal care compared to periods of lower unemployment (Aparicio and Gonzalez 2014, Dehejia and Lleras-Muney 2004).

Because of the large amounts of EZ money and the geographic limits on where EZ funds can be spent, the neighborhood effects of the program on health are potentially large. High crime neighborhoods are associated with less physical activity (Wen, Browning, and Cagney 2007) and worse health (Browning, Cagney, and Iveniuk 2012), while improving the neighborhood in which one lives can have substantial effects on an individual's well-being and general health (Ludwig et al. 2012, 2013).

The multi-pronged nature of the EZ program makes it particularly interesting to study. While disentangling these mechanisms may be more difficult, the potential health effects of the EZ program may be larger than that of an income transfer program or a macroeconomic shock because of the additional pathways described above.

\section{Data}


I use restricted-access, state-specific, geocoded vital statistics natality data. The EZ program application and qualification process was based on 1990 census tract level characteristics, and the program was implemented at the census tract level. These natality data sets are the only ones available at such a fine geographic level that also contain a sufficient sample size to analyze EZ program effects. They contain the universe of births in these areas.

These geocoded data are only available on a state by state basis. I created a unique dataset consisting of geocoded data from 9 cities and states: Colorado, Florida, Kentucky, Ohio, Oregon, Pennsylvania, Texas, the City of Chicago and New York City. Pennsylvania contains both treatment and control zones. ${ }^{7}$ Because of data availability I limit my analysis to Chicago, New York, and Philadelphia. ${ }^{8}$ The years for which I have these data are 1990-2002. The EZ program began in 1995, so I have pre-EZ data for 1990-1994 and post-EZ data for 1995-2002 from which to analyze the program effects. ${ }^{9}$

Vital Statistics Natality data from all states listed above contain birth weight and parental demographic characteristics such as race, ethnicity, age, and educational attainment. These data also contain prenatal care measures, including whether a woman received any prenatal care and the month in which care began, whether a woman drinks or smokes during pregnancy, gestational period, a plural birth indicator, and geocoded addresses to identify the census tract of the mother's residence. ${ }^{10}$ Not all variables are available from all states. Appendix Table 1 provides a chart describing the data available from each state. I limit my sample

\footnotetext{
${ }^{7}$ I applied for data from all EZs, but only Chicago, New York, and Philadelphia zones provided me with these data.

${ }^{8}$ Philadelphia and Camden were technically one EZ, but they were managed by separate entities with input from separate state and city governments and received a predetermined amount of the block grants.

Philadelphia received $\$ 79$ of the $\$ 100$ million. I do not have New Jersey data so I treat the Philadelphia EZ as if it were the whole EZ based on its receipt of the majority of funds and its separate management.

${ }^{9}$ Because I use date of conception rather than date of birth, I technically have data from 1989-2001.

${ }^{10}$ In some cases, states provided me with raw maternal address data that I geocoded to find the exact latitude and longitude of residence from which I calculated census tract of residence using ArcGIS software by Esri.
} 
to singular births because of higher incidence of low birth weights and additional risks associated with plural births. ${ }^{11}$ I also use Census tract level summary files of neighborhood characteristics from the 1990 and 2000 decennial Censuses and the American Community Survey 5-year file (2005-2009) to create tract-level demographic characteristics.

I use the year of conception, calculated from the estimated gestational age, rather than the year of birth for all fertility rate calculations. I similarly use year of conception for all birth outcomes, although I perform additional analyses using year of birth. ${ }^{12}$

\section{Empirical Methods}

I estimate difference-in-differences models as my basic specification, comparing outcomes in treated areas to control areas using time periods before and after the treatment:

$$
Y_{i s t}=\alpha_{1}+\alpha_{2}(E Z * \text { Post })_{i s t}+\beta X_{i s t}{ }^{\prime}+\delta_{c}+\gamma_{t}+\varepsilon_{i s t},
$$

where $\mathrm{i}$ indexes children or women, $\mathrm{s}$ indexes zone, and $\mathrm{t}$ indexes year. Y refers to birth outcomes including fertility rates per 1,000 women aged 15 to $44,{ }^{13}$ birth weight, very low birth weight (<1500 grams), low birth weight (<2500 grams) and gestational age of at least 37 weeks. Other outcomes include whether a mother received any prenatal care, the month mothers received prenatal care for the first time, and smoking status of mothers. $E Z$ is an indicator variable that takes a value of 1 if a mother resided within a census tract that received round I EZ status (i.e., is in the treatment group) when she gave birth and Post is an indicator variable that is 1 if a baby was born after the implementation of the EZ program in 1995. $\alpha_{2}$, the coefficient on the interaction term, is the main parameter of interest. The main effect of the variable $E Z$ is subsumed by the census tract fixed

\footnotetext{
${ }^{11}$ Over 97 percent of births in the US over the study window were singular births (http://www.cdc.gov/nchs/data/databriefs/db80.pdf accessed June 12, 2014)

${ }^{12}$ States collect these data at birth. I assume mothers lived in the same residence at the time of conception.

${ }^{13}$ Because fertility is a population-level measure it thus requires aggregating data up to the EZ or control zone level and including zone-level fixed effects.
} 
effects $\left(\delta_{c}\right)$. Year fixed effects $\left(\gamma_{t}\right)$ absorb the main effect of the variable Post. $X$ is a vector of individual demographic characteristics contained in Table 1. I cluster standard errors in all regressions at the EZ or control zone level, as this is the level of treatment, to allow for serial correlation of error terms. I also calculate age-specific models of fertility rates for ages 15 to 19,20 to 24,25 to 29,30 to 34 , 35 to 39 , and 40 to 44 .

I use a control group composed of areas that applied for but did not receive Round I EZ funding, or areas that received later round EZ funding. These areas are similar to EZs in that all qualified for EZ status. They also were chosen by their respective cities as application zones, such that if there exists selection into being included as an application tract, as long as the selection is consistent across cities this should not be a concern. Others use a similar set of controls (Busso, Gregory, and Kline 2013, Hanson 2009, Hanson and Rohlin 2011, 2013, Reynolds and Rohlin 2013).

Ham et al. (2011) raise the concern that using controls from other cities and states may fail the conditional independence assumption: even after controlling for observables such as demographic characteristics of the zones and of the mothers giving birth in these zones, unobservable characteristics in these areas may still differentially affect outcomes. Yet same city control areas may mask geographic spillover effects, either positive or negative, of the EZ program. In the case of positive spillovers, this would bias my estimates towards zero. I perform robustness checks using same city control areas excluding tracts adjacent to EZs.

The main assumption of the difference-in-differences model is that absent the EZ program these areas would have continued to follow common trends in the post period. If areas are granted an EZ in response to worsening (improving) outcomes in these areas, my estimates will be biased towards zero (finding an effect). Figure 2 provides annual unadjusted-means of fertility rates by EZ status 
and monthly unadjusted-means for birth weight, low and very low birth weight, and full-term births, with fitted lines demonstrating the pre-treatment trends. From these figures, EZs and control areas appear to be trending in similar ways in the period prior to the policy which suggests common trends may be a reasonable assumption. ${ }^{14}$ To the extent that slight differences exist in pre-trends by EZ status in Figure 2, I use synthetic control methods which I describe below to create a better pre-period match on trends.

A part of the common trends assumption is that no unobserved shocks occur at the same time as the EZ program that differentially affects trends in the outcome variable in treated or control zones. ${ }^{15}$ I estimate models using an alternate same city control group to account for potential unobserved shocks. Considering that these areas are similarly economically-disadvantaged areas and from the same cities as the EZs, for this assumption to fail in this context cities would have had to have implemented additional programs only in the EZ section of the city at the same time as the EZ program. ${ }^{16}$

To account for concerns with the difference-in-differences method, I employ synthetic control models (Abadie, Diamond, and Hainmueller 2010). I create a weighted control area matched on pre-EZ trends, including the outcome of interest, such that the vector of weights (W) minimizes:

$$
\left\|X_{1}-X_{0} W\right\|_{v}=\sqrt{\left(X_{1}-X_{0} W\right)^{\prime} V\left(X_{1}-X_{0} W\right)}
$$

where $X_{1}$ is an unweighted vector of pre-intervention characteristics of the treatment zones and $X_{0}$ denotes a similar vector for control zones. The pool of

\footnotetext{
${ }^{14}$ I present similar figures for each EZ separately in Appendix Figures A1-A3.

${ }^{15}$ A potential contemporaneous change occurring during this time period is the expansion of state Medicaid systems via federal waivers for expanding family planning coverage (see Kearney and Levine 2009). However, Pennsylvania never applied for this waiver, and New York and Illinois did not apply for these waivers until 2002, after my study period, making it unlikely to affect fertility analyses in this paper. ${ }^{16}$ Potential weaknesses of the difference-in-differences model include problems associated with a small number of clusters because I only have 3 treatment zones and 16 control zones (Bertrand, Duflo, and Mullainathan 2004). Standard errors in this circumstance may be underestimated, affecting statistical significance. Uncertainty about whether the control group accurately captures the counterfactual trend of treated areas, had the treatment not occurred, is another concern (Abadie, Diamond, and Hainmueller 2010).
} 
control areas consists of all application and future zones, but if a control area is trending differently from the treatment, it can receive zero weight. This method creates a weighted comparison group that minimizes the root mean squared error of the outcome variables in the pre-treatment period, which is the standard deviation in the difference between the actual outcome value of the treatment group and the predicted outcome value of the synthetic control group (Abadie, Diamond, and Hainmueller 2010).

I estimate synthetic control models separately by outcome. The basic specification adjusts for the pre-period outcome of interest in each pre-EZ year, and the average of the following variables over the same pre-period: mother's race and ethnicity, gender of the baby, census tract level demographic characteristics for poverty level, race, gender, and educational attainment. I include each year separately for the outcomes because it creates the best pretreatment match.

The main strengths of this method are it creates a matched control group that follows similar pre-trends in terms of the outcome of interest, and it allows for rigorous inference testing. Because the control areas follow similar pre-trends, they are plausibly a better counterfactual representation of what one would expect to have happened to outcomes in Round I EZs absent the treatment.

The inference testing consists of systematically assigning treatment to each control zone, creating a synthetic control group using the actual EZ as a control area as well as the full pool of control zones, minus the zone assigned to treatment. As in the case of the EZ, I separately calculate the average treatment effect and the root mean squared prediction error in the post-period ${ }^{17}$ of assigning treatment to each control zone. This creates a distribution of average treatment effects (and ratios of root mean squared prediction errors) by which to evaluate

\footnotetext{
${ }^{17}$ I divide the post root mean squared error by the pre root mean squared error and create a distribution of these ratios (Abadie, Diamond, and Hainmueller 2010). Thus, if areas had a poor pre-trend match, this method implicitly controls for this difference.
} 
the average treatment effect of the actual EZ program. So if there are 30 average treatment effects and the EZ effect is larger than 27 of the control area average treatment effects, the estimate is statistically significant at the $10 \%$ level.

For this method to fail, one would have to assume that EZs were selected endogenously because they were improving before the EZ program began and additionally that the rate of improvement changed differentially following the EZ program for reasons entirely separate from the EZ program. This is essentially a second derivative difference in the post period. That is, even after controlling for trends using synthetic control models, the EZs improved even more than places that were trending similarly in the pre-period following the EZ program implementation.

\subsection{Summary Statistics}

In Table 1, I find that areas that received EZ status differed from control zones on a number of demographic characteristics and birth outcomes. Note that trends, and not levels, are what matter in the difference-in-differences model.

The unadjusted difference-in-differences in Column 7 show fertility rates in EZs decrease by nearly 20 births per 1,000 women compared to control zones. Moreover, birth weight in EZs increase by 33 grams while low birth weight rates decrease by 1.3 percentage points and full-term births increase by 1.6 percentage points relative to control zones. Trends in racial composition of mothers are similar across EZs and control areas. Thus, there appears to be a change in fertility and birth outcomes with little evidence of a change in the composition of mothers. The remainder of the paper examines whether these patterns remain when employing more advanced empirical methods.

\section{Results}

6.1. Difference-in-differences and Synthetic Control Estimates

\subsubsection{Baseline Results}


In Table 2, I present fertility and birth outcome results from estimating equations (1) and (2). In Panel A, I use areas that applied for but did not receive the EZ program or areas that received the EZ program at a later point in time as control zones, my preferred control group. Panel B uses a control group of individuals who lived in census tracts within the same city as EZs with poverty rates above 20 percent that did not apply for the EZ program. These were similarly economically-disadvantaged areas that, based on their poverty rates, qualified for the EZ program. For each control group I estimate both differencein-differences and synthetic control models. Each cell in the table presents results from a separate regression.

In Panel A using difference-in-differences models, fertility rates in EZs decrease by 10 births per 1,000 women aged 15 to 44 compared to control zones, an 11 percent decrease in fertility rates. Birth weight increases by 26 grams in EZs compared to control zones. While these relative increases in birth weight are statistically significant at conventional levels, the magnitude is small. Compared to the mean birth weight of approximately 3200 grams, a 26 gram increase is equivalent to a 0.8 percent increase in birth weight. However, when I examine this effect closer using clinical birth weight thresholds, a picture of distributional effects emerges.

EZs decrease low birth weight rates by 0.8 percentage points. The pretreatment mean for low birth weight is approximately 10 percent, so this is an 8 percent decrease. The EZ program appears to have little effect on rates of very low birth weights in zones compared to control zones. Previous work studying the earned income tax credit (Hoynes, Miller, and Simon 2015) and the initial roll-out of food stamps (Almond, Hoynes, and Schanzenbach 2011) suggests these income-targeting programs decrease low birth weight rate by between 1 and 5 percent, which is slightly smaller than the effect size I find.

\subsubsection{Synthetic Control and Inference Results}


Because the difference-in-differences model does not match on trends in the pre-period, I use synthetic control methods as a robustness test. This method creates a control group with a similar pre-trend in the outcome variable compared to the EZ group. Row (2) of Table 2 summarizes the results for fertility rates and birth outcomes using the synthetic control method and inference testing as described in section 5. The first row of parenthetical numbers under row (2) presents implied p-values of the EZ average treatment effect evaluated against the distribution of placebo average treatment effects, while the row directly beneath that contains implied p-values of the ratio of post to pre-root mean squared prediction error for the $\mathrm{EZ}$ compared to the distribution from inference testing.

The results for fertility rates are robust to synthetic control methods. Results for additional birth outcomes provide estimates of similar magnitudes to the difference-in-differences estimates. Birth weight in EZs increases by nearly 18 grams relative to synthetic control models, although this estimate is not statistically significant. The effect of EZs on low birth weight implies a 1.3 percentage point reduction in low birth weight rates compared to the synthetic control and a 1.8 percentage point increase in full-term births. These estimate are statistically significant using the root mean squared error distribution.

Figure 3 presents fertility rate results from Table 2, Panel B graphically. ${ }^{18}$ Panel B of Figure 3 shows the difference between treatment and synthetic control groups for models in which each control is designated as the treatment. Fertility rates decrease following the EZ program and continue to decrease in the years after, with an implied reduction in fertility rates of 15 births per 1,000 females compared to synthetic controls. Importantly, the reduction in fertility rates in EZs, the solid line in Figure 3, Panel B, is larger than the placebo effects of assigning treatment to any of the control zones, depicted in the dotted lines. Panels C and D

\footnotetext{
${ }^{18}$ Appendix Figures 4-7 provide similar figures of synthetic control models for birth weight, low birth weight, very low birth weight, and full-term.
} 
present the cumulative distribution of average treatment effects and ratio of postto pre-root mean squared prediction errors, respectively, from assigning treatment systematically to each control. The vertical line shows the estimate for the actual EZs. In each case, the vertical line is at the extreme, lending credence to the statistical significance of these estimates.

\subsubsection{Same City Control Areas}

As a robustness check, I evaluate the EZs compared to a control group consisting of births occurring to mothers who lived in Chicago, New York, and Philadelphia using a difference-in-differences model in Panel B of Table 2. Using same city control groups ostensibly reduces the concern that unobservable differences between control groups and treatment areas may affect outcomes. Figure 1 presents areas in each city with poverty rates above 20 percent as well as areas that receive the EZ program. I exclude births to mothers living in census tracts adjacent to tracts that received the program to ensure that any geographic spillover effects of the program do not confound my estimates.

These estimates are consistent with the main difference-in-differences results. Fertility rates decrease by 11 births per 1,000 women between ages 15 and 44. Birth weight and low birth weight results are similar to the main results in magnitude, although neither estimate is statistically significant. The effect size for full-term is less than half the size of that in Panel A and lacks statistical significance.

Results using synthetic control methods with same city control zones, which control for pre-trends and potential unobserved city-wide shocks, are presented in row (4) of Table 2. Fertility results are robust to this specification. Birth outcomes are of similar magnitude to those in row (3) and are consistent with the results in Panel A. These estimates provide supporting evidence that the effects I find in Panel A reflect the true program effects on health.

\subsection{Mechanisms}


The difference-in-differences results in Table 2 present the average treatment effect of the EZ program on birth weight. Despite using clinically relevant thresholds for low and very low birth weight, these results do not completely illuminate the birth weight distribution effects of the EZ. Using an unconditional quantile regression model (Firpo, Fortin, and Lemieux 2009), I estimate the effect of the EZ program on every fifth percentile of the birth weight distribution, including the same variables as in the main difference-in-differences specification. Figure 4 shows that birth weight increases from the EZ program are concentrated among the lowest quantiles of the birth weight distribution.

In Table 3, I explore potential mechanisms through which EZs may improve birth outcomes using a sample of Chicago, New York, and Philadelphia EZs and my preferred control sample. These estimates provide suggestive evidence of improved prenatal care in EZs: the probability of receiving no prenatal care decreases in EZs compared to control zones by 1.8 percentage points and time to receipt of a first prenatal care visit decreases by 0.16 months, or nearly a week. However, neither of these results is statistically significant.

Smoking in EZs increases relative to control areas by 2 percentage points, a 15 percent increase. If anything, this increase in smoking should make birth outcomes worse as smoking while pregnant is associated with lower birth weight (Currie, Neidell, and Schmeider 2009).

An additional mechanism through which the EZ program may affect health is through compositional change in these zones. However, there is little evidence of differential compositional change following the EZ program compared to control areas. In Table 4, I present the proportion of individuals still living in the same house, the same county, and the same state as they were 5 years prior to the 1990 and 2000 decennial censuses by EZ status. The last column of this table provides unadjusted difference-in-differences calculations for each row. 
The results show no differential change in the probability of remaining in the same area following the EZ program.

In Table 1, Panel B, I find little evidence of compositional change specifically among mothers corresponding to EZ adoption. The unadjusted difference-in-differences in Column 7 show that trends in racial composition of mothers are similar across EZs and control groups. Educational attainment of expecting mothers does not change in statistically significant ways, although there is some evidence of EZ mothers becoming slightly more educated than non-EZ mothers. Mothers in EZs are 0.3 years older than mothers in control zones at birth following the EZ program, a statistically significant but modest difference.

To test for demographic shifts, I use data from before the EZ program and regress each outcome variable on maternal age, race and ethnicity, educational attainment, and child's gender. These regressions include all births conceived before 1995. Using these estimates, I predict the value of each dependent variable over the entire sample, not just the pre-period sample used in the original regression. Next, using a difference-in-differences model, I regress the predicted outcome on an indicator variable for whether the birth occurred in an EZ, the interaction of the variable EZ and Post, an indicator for whether the baby was conceived in 1995 or later, and year fixed effects which subsume the main effects of the variable Post.

Because fertility is a population-level measure, I create predicted fertility rates by categories of age and race based on fertility rates in 1990. I assign predicted fertility as the demographically weighted predicted fertility in zone $s$ :

$$
\text { Predicted Fertility } \text { Pr }=\sum_{r=1}^{4}\left(\sum_{k=1}^{4} \text { fertility rate }_{r k} * P_{r k s}\right)
$$

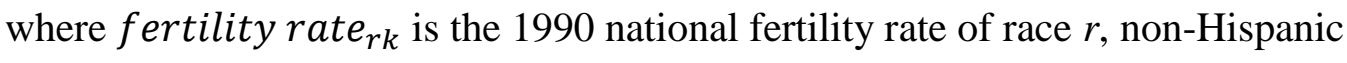
white, non-Hispanic black, Hispanic, or other, and age $k$, a vector of age bins 15$24,25-29,30-34$, and 35-44. $P_{r k s}$ is the proportion of females between the ages of 15 and 44 of a particular race $r$, in age bin $k$, living in zone $s$. 
The results for predicted fertility, presented in Table 5, imply that based on the age and race of mothers in EZs, I would expect little change in fertility rates following the EZ program implementation in EZs compared to control zones. For birth outcomes, the model predicts that birth weight in these areas should decrease slightly, low birth weight should increase slightly, and full-term births should be unaffected relative to control areas. The actual results from the main difference-in-differences specification are oppositely signed and statistically significant. These results imply demographic compositional changes cannot explain the decrease in fertility rates and improvements in birth outcomes following the EZ program. ${ }^{19}$

\subsection{Heterogeneous Treatment Effects}

\subsubsection{Fertility Analysis by Age}

I show in section 6.1 that fertility rates decrease in EZs. Whether this is simply a timing effect in that women delay fertility to a later age, or an overall decrease in fertility requires an age-specific analysis. I estimate the same models as in Table 2 separately by age groups 15 to 19,20 to 24,25 to 29,30 to 34,35 to 39, and 40 to 44 . In Table 6, I find the largest decreases in fertility rates in EZs among those aged 20 to 24 and 25 to 29 . Fertility decreases by 18 to 19 births per 1,000 women among those aged 20 to 24 and by 19 to 20 births among those aged 25 to 29 compared to control zones. EZs decrease fertility rates among those aged 30 to 34 by approximately 7 births per 1,000 . These results are robust to alternate control groups and synthetic control methods. Finally, there is some evidence that EZs decrease fertility rates among those aged 15 to 19 , but these results are not robust across specifications. Importantly, these results suggest that the fertility decrease in EZs is not just a timing effect, but a decrease in total fertility.

\subsubsection{Subgroup Analysis by Education}

${ }^{19}$ Appendix Table 3 contains results of a similar analysis using a same city control group. 
To examine heterogeneous treatment effects, in Table 7 I separately estimate equation (1) by educational attainment and race. These estimates compare EZs to my preferred control group of application areas and future EZs for all panels of Table 7. I cannot estimate fertility rates by educational attainment because of imprecise estimates of the denominator of women aged 15 to 44 by educational attainment. ${ }^{20}$

For the sample of mothers with a high school degree or less, displayed in Panel A of Table 7, I find nearly identical point estimates and statistical significance compared to the main results in Table 2. That this estimate is robust to limiting the sample to less educated women is further evidence that compositional changes are not driving my results. Panel B presents results using only mothers with at least some college education. These estimates demonstrate that birth weight increases by 43 grams among those living in EZs compared to those living in control zones, with little effect on low birth weight. These estimates of low birth weight are similar to those in Hoynes, Miller, and Simon (2015), who find decreases of between 1 and 5 percent among less-educated women.

\subsubsection{Subgroup Analysis by Race}

Because of differences in birth weights and the incidence of low birth weight babies by race, ${ }^{21}$ I estimate models separately by mother's race in Panels C through $\mathrm{E}$ of Table 7. For blacks, estimates are of both a similar magnitude and statistical significance compared to those of the main difference-in-differences estimates. The point estimate on low birth weight is slightly larger than the main results, a 1.3 percentage point decrease, but the rate of low birth weight among blacks is 14 percent in the pre-period implying a similar 9 percent reduction in

\footnotetext{
${ }^{20}$ Estimates of the population of women aged 15 to 44 come from decennial Census summary files. These summary files also collect data on the educational attainment of individuals aged 25 or older but do not collect educational attainment by gender and age groups. Any attempt at classifying educational attainment for those under age 25 would be inherently biased.

${ }^{21}$ Black babies have rates of low birth weight nearly twice that of white babies (See e.g. Reichman 2005).
} 
low birth weight due to EZs. For Hispanics, the estimates imply little effect of EZs on fertility rates, but similar improvements in both birth weight and low birth weight rates in EZs compared to control areas. Conversely to other races and ethnicities, whites, who compose just 4 percent of the EZ sample, do not appear to be affected by the EZ program. Despite similar reductions in fertility rates, the point estimate on birth weight is negative but not statistically significant.

\subsection{Additional Robustness Checks}

I perform synthetic control methods matching on both trend and level in Appendix Table 4. The results are consistent with my preferred specification matching on just level. I also perform the main analysis using a control pool of all 24 control zones in Appendix Table 5, using a difference-in-differences model in Panel A, a synthetic control model matched on trend in Panel B, and trend and level in Panel C. These results are fairly robust across specifications. I perform all analyses using the year of birth, rather than the year of conception to classify pregnancies relative to the EZ program in Appendix Table 6. I do this because vital statistics data contain residence at the time of birth, not time of conception. These results are both qualitatively and quantitatively similar to those using time of conception. In Appendix A, I present results separately by EZ.

\section{Conclusions}

This study provides the first estimates of the effect of the empowerment zone program on fertility and birth outcomes. The EZ program is a federal program that potentially increases household income and provides large scale changes in neighborhood infrastructure. It is one of the largest place-based program ever implemented in the US and health effects are an important metric by which to explore the overall effects of this program. Overall, my estimates suggest the EZ program decreases fertility and improves birth outcomes among zone residents compared to control areas. 
While I find substantial gains in birth weight and reductions in low birth weight that are similar to those found for the earned income tax credit (Hoynes, Miller, and Simon 2015) and the initial roll-out of food stamps (Almond, Hoynes, and Schanzenbach 2011), important distinctions between the works remain. First, Hoynes, Miller, and Simon (2012) find a smaller effect of an increase in income on overall birth weight and the effects on low birth weight are specific to a lesseducated, single mother sample. My results for low birth weight are similar in magnitude to theirs, but I also find substantial increases in birth weight. Also, fertility rates decreased substantially in EZs while the earned-income tax credit had little effect on fertility rates (Baughman and Dickert-Conlin 2009).

Interestingly, the per capita costs of the EZ program are much lower than those of the earned income tax credit and the Supplemental Nutrition Assistance Program on an annual basis. ${ }^{22}$ By 2000 , approximately $\$ 600$ million in federal funds had been spent on the EZ program, in areas with a total population of approximately 700,000 individuals or $\$ 850$ per capita over 6 years. In 201128 million families claimed the earned income tax credit at a total program cost of $\$ 60$ billion while 45 million individuals were enrolled in SNAP at a cost of $\$ 72$ billion. These annual per capita costs are between $\$ 1000$ and $\$ 2000$.

The income effects of the EZ program (Busso, Gregory, and Kline 2013, Ham et al. 2011) likely led to an increase in demand for higher quality children, decreasing fertility rates and leading parents to invest more in the birth weight production function. My sample consists nearly entirely of less-educated women living in high poverty, high unemployment areas so any improvements in the labor market likely led to the substitution effect swamping the income effect of higher wages on fertility (Heckman and Walker 1990, Perry 2004). Moreover, fewer babies born in these areas would reduce demand for prenatal services, potentially affecting overall health by increasing availability of health services.

${ }^{22}$ The Supplemental Nutrition Assistance Program is the current name of the food stamp program. 
Parents may invest more in the birth weight production function through more or higher quality prenatal care, or through health behaviors that my model cannot capture such as eating healthier or exercising more while pregnant (Aparicio and Gonzalez 2014). Increases in full-term births may partially explain improvements in birth weight and low birth weight as gestational age is associated with intra-uterine growth and increased birth weight (see e.g. Olsen et al. 2010). This paper focuses on the short-term health effects of the EZ program. However, the fetal origins literature provides a fairly strong prior for predicting long-term health and labor market effects of the EZ program. This program also reduced poverty, improved labor markets, and improved infrastructure in these areas. The potential long-term benefits of reducing low birth weight together with the neighborhood-level gains in labor market outcomes could have staggering welfare effects in these areas and may justify the cost of the EZ program. 


\section{References}

Abadie, Alberto, Alexis Diamond, and Jens Hainmueller. 2010. "Synthetic Control Methods for Comparative Case Studies: Estimating the Effect of California's Tobacco Control Program." Journal of the American Statistical Association 105 (490): 493-505.

Almond, Douglas, and Janet Currie. "Killing Me Softly: The Fetal Origins Hypothesis.” Journal of Economic Perspectives 25, no. 3 (2011): 153-72.

Almond, Douglas, Joseph J. Doyle, Jr., Amanda Kowalski, and Heidi Williams. 2010. "Estimating Marginal Returns to Medical Care: Evidence from AtRisk Newborns." Quarterly Journal of Economics 125 (2): 591-634.

Almond, Douglas, Hilary W. Hoynes, and Diane Whitmore Schanzenbach. 2011. "Inside the War on Poverty: The Impact of Food Stamps on Birth Outcomes." Review of Economics and Statistics 93 (2): 387-403.

Aparicio, Ainhoa, and Libertad Gonzalez Luna. 2014. "Newborn health and the business cycle: Is it good to be born in bad times?" Barcelona GSE Working Paper Series 702.

Baughman, Reagan, and Stacy Dickert-Conlin. 2009. "The Earned Income Tax Credit and Fertility." Journal of Population Economics 22 (3): 537-63.

Becker, Gary. 1960. "An Economic Analysis of Fertility." In Demographic and Economic Change in Developed Countries. National Bureau of Economic Research, 209-240. Columbia University Press.

Bertrand, Marianne, Esther Duflo, and Sendhil Mullainathan. 2004. "How Much Should We Trust Difference-in-differences Estimates?" Quarterly Journal of Economics 119 (1): 249-75.

Black, Dan, Natalia Kolesnikova, Seth Sanders, and Lowell Taylor. 2013. “Are Children "Normal"?" Review of Economics and Statistics 95 (1): 21-33.

Browning, Christopher R., Kathleen A. Cagney, James Iveniuk. 2012. "Neighborhood stressors and cardiovascular health: Crime and C-reactive protein in Dallas, USA" Social Science and Medicine 75 (7): 1271-1279.

Busso, Matias, Jesse Gregory, and Patrick Kline. 2013. "Assessing the Incidence and Efficiency of a Prominent Place Based Policy." American Economic Review 103 (2): 897-947.

Corman, Hope, and Michael Grossman. 1985. "Determinants of Neonatal Mortality Rates in the U.S.: A Reduced Form Model." Journal of Health Economics 4 (3): 213-36.

Currie, Janet. 2009. "Healthy, Wealthy, and Wise: Socioeconomic Status, Poor Health in Childhood, and Human Capital Development." Journal of Economic Literature, 47 (1): 87-122.

Dehejia, Rajeev, and Adriana Lleras-Muney. 2004. "Booms, Busts, and Babies' Health," Quarterly Journal of Economics 119 (3): 1091-1130. 
Firpo, Sergio, Nicole M. Fortin, and Thomas Lemieux. "Unconditional Quantile Regressions.” Econometrica 77, no. 3 (May 2009): 953-73.

Government Accountability Office. 2010. "Information on Empowerment Zone, Enterprise Community, and Renewal Community Programs: Briefing for Congressional Addressees," at http://www.gao.gov/new.items/d10464r.pdf.

Ham, John C., Charles Swenson, Ayse Imrohoroglu, and Heonjae Song. 2011. "Government Programs Can Improve Local Labor Markets: Evidence from State Enterprise Zones, Federal Empowerment Zones and Federal Enterprise Community.” Journal of Public Economics 95 (7-8): 779-97.

Hanson, Andrew. 2009. "Local Employment, Poverty, and Property Value Effects of Geographically-Targeted Tax Incentives: An Instrumental Variables Approach.” Regional Science and Urban Economics 39 (6): 721-31.

Hanson, Andrew, and Shawn Rohlin. 2011. "Do Location-Based Tax Incentives Attract New Business Establishments?" Journal of Regional Science 51 (3): 427-49.

—. 2013. "Do Spatially Targeted Redevelopment Programs Spillover?" Regional Science and Urban Economics 43 (1): 86-100.

- 2011. "The Effect of Location-Based Tax Incentives on Establishment Location and Employment across Industry Sectors." Public Finance Review 39 (2): 195-225.

Heckman, J. J., and J. R. Walker. 1990. "The Relationship Between Wages and Income and the Timing and Spacing of Births: Evidence from Swedish Longitudinal Data," Econometrica 58: 1411-41.

Hoynes, Hilary W., Douglas L. Miller, and David Simon. 2015. "Income, the Earned Income Tax Credit, and Infant Health."American Economic Journal: Economic Policy, 7(1): 172-211.

Kearney, Melissa S., and Phillip B. Levine. 2009. "Subsidized Contraception, Fertility, and Sexual Behavior." Review of Economics and Statistics 91 (1): 137-51.

Krupka, Douglas J., and Douglas S. Noonan. 2009. "Empowerment Zones, Neighborhood Change and Owner-Occupied Housing." Regional Science and Urban Economics 39(4): 386-96.

Lindo, Jason M. 2010. “Are Children Really Inferior Goods? Evidence from Job Displacement-driven Income Shocks.” Journal of Human Resources 45 (2): 301-27.

Lovenheim, Michael F., and Kevin J. Mumford. 2013. "Do Family Wealth Shocks Affect Fertility Choices? Evidence from the Housing Market." Review of Economics and Statistics 95 (2): 464-75.

Ludwig, Jens, Greg J. Duncan, Lisa A. Gennetian, Lawrence F. Katz, Ronald C. Kessler, Jeffrey R. Kling, Lisa Sanbonmatsu. 2012. "Neighborhood 
Effects on the Long-Term Well-Being of Low-Income Adults." Science 337 (6101): 1505-10.

. 2013. "Long-Term Neighborhood Effects on Low-Income Families: Evidence from Moving to Opportunity." NBER Working Paper Series 18772.

Oakley, Deirdre, and Hui-Shien Tsao. 2006. "A New Way of Revitalizing Distressed Urban Communities? Assessing the Impact of the Federal Empowerment Zone Program." Journal of Urban Affairs 28 (5): 443-71.

Olsen, Irene E., Sue A. Groveman, M. Louise Lawson, Reese H. Clark and Babette S. Zemel. 2010. "New Intrauterine Growth Curves Based on United States Data" Pediatrics 125: e214-24.

Perry, Cynthia. 2004. "Economic Well-Being and the Family." http://dspace.mit.edu/handle/1721.1/29427.

Reichman, Nancy. 2005. "Low Birth Weight and School Readiness," Future of Children 15 (1): 91-116.

Reynolds, C Lockwood, and Shawn M Rohlin. "The Effects of Location-Based Tax Policies on the Distribution of Household Income: Evidence from the Federal Empowerment Zone Program," unpublished manuscript (2013).

Roback, Jennifer. 1982. "Wages, Rents, and the Quality of Life," Journal of Political Economy 90 (6): 1257-1278.

Russell, Rebecca, Nancy Green, Claudia Steiner, Susan Meikle, Jennifer Howse, Karalee Poschman, Todd Dias, Lisa Potetz, Michael Davidoff, Karla Damus, and Joann Petrini, 2007. "Cost of Hospitalization for Preterm and Low Birth Weight Infants in the United States," Pediatrics 120: e1-e9.

Wen, Ming, Christopher Browning, Kathleen A. Cagney. 2007. "Neighbourhood Deprivation, Social Capital and Regular Exercise during Adulthood: A Multilevel Study in Chicago." Urban Studies 44 (13): 2651-71. 
Figure 1: Map of Chicago, the Chicago Empowerment Zone, and the Census Tracts that Qualified for Empowerment Zone Status

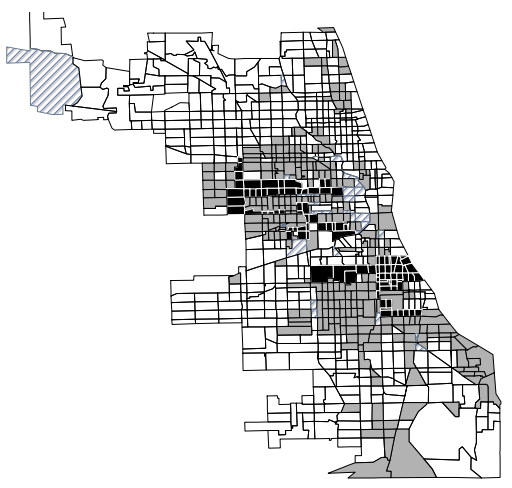

(a) Chicago

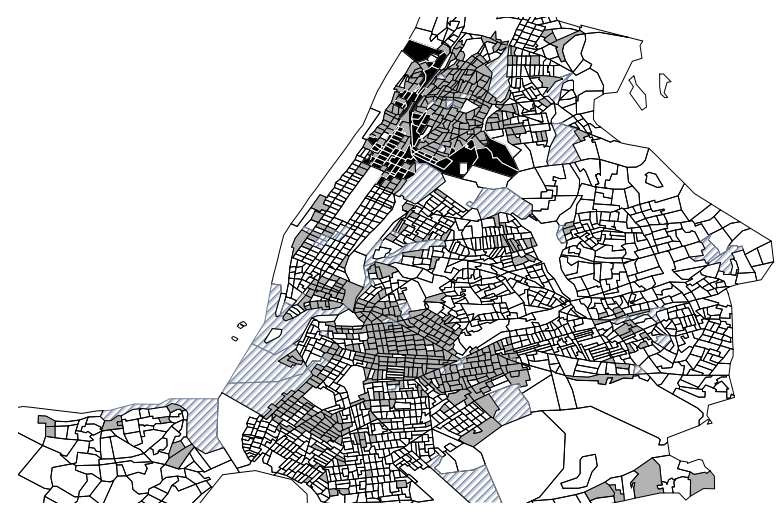

(b) New York

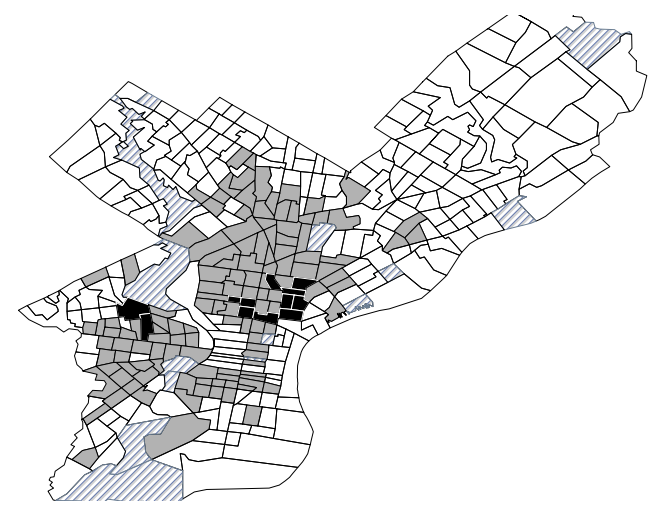

(c) Philadelphia

Source: Poverty rates are from the 1990 Decennial Census. Empowerment Zone is shown in black. Areas that qualified for EZ status, with poverty rates above $20 \%$ and at least 500 inhabitants, are denoted in gray. Striped areas did not qualify because of populations below 500 individuals. White areas did not have poverty rates above $20 \%$. 


\section{Figure 2: Average Fertility Annually and Birth Outcomes Monthly by Empowerment Zone Status}

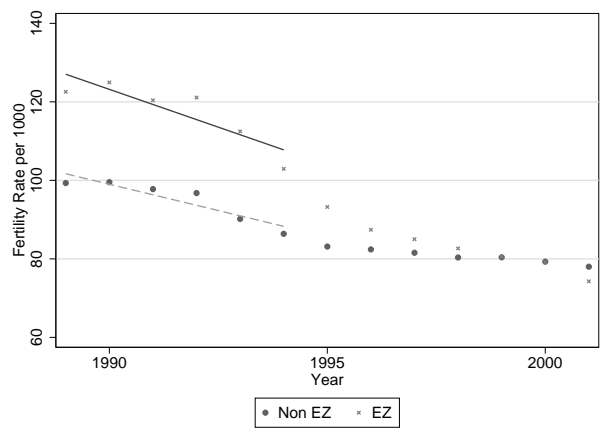

(a) Fertility Rate

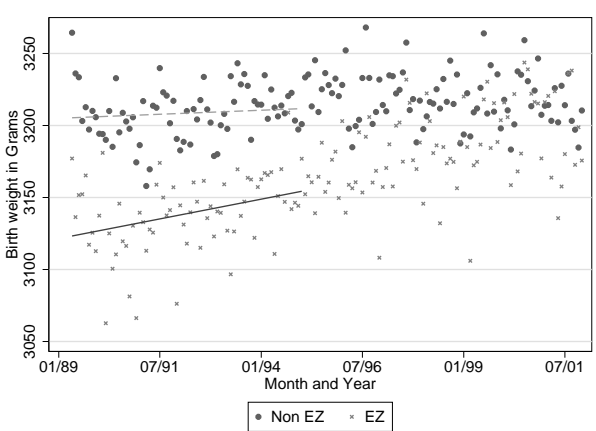

(b) Birth Weight

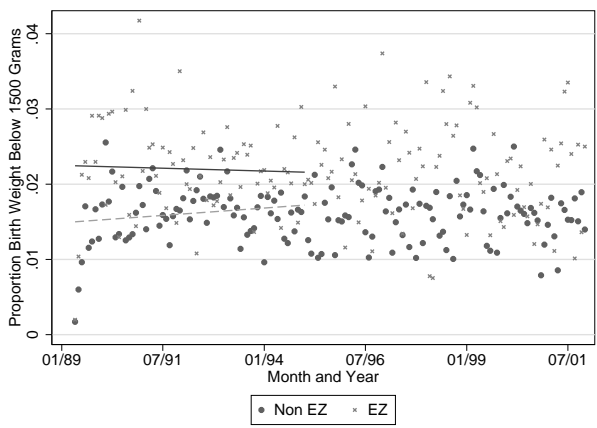

(d) Very Low Birth Weight

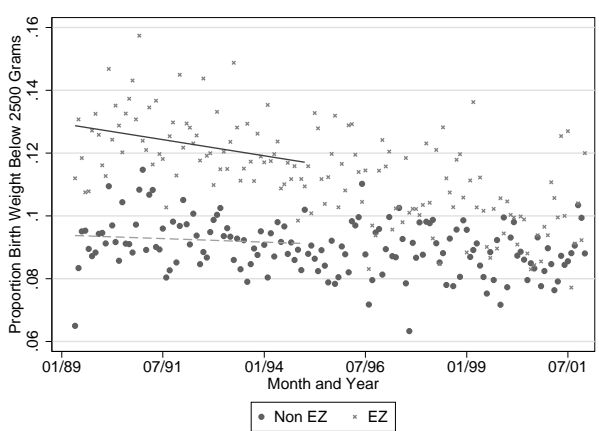

(c) Low Birth Weight

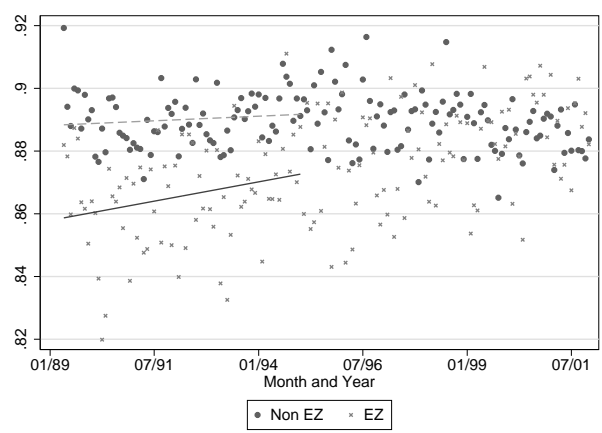

(e) Full-term

Source: Fertility rates collapsed by year, birth weight, low birth weight rates, and fullterm birth rates collapsed by month, with linear trend lines for the pre-empowerment zone periods. Chicago, New York, and Philadelphia EZs compared to the limited sample of controls (Busso et al. 2013), excluding controls from cities with populations less than 100,000 or with less than 10 census tracts in the original application zone. 


\section{Figure 3: The Effect of Empowerment Zone Status on Fertility Using Synthetic Control Methods}

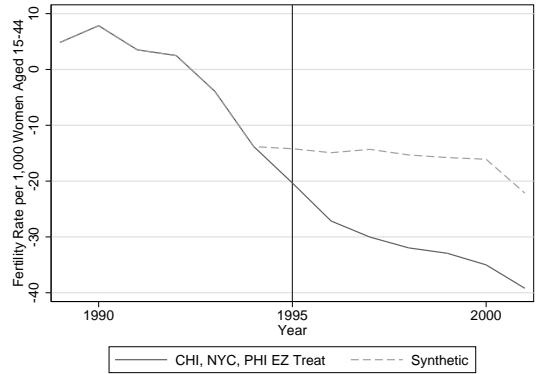

(a) EZ estimate

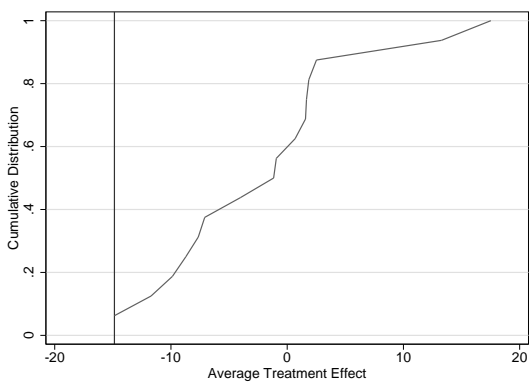

(c) Average Treatment Effect

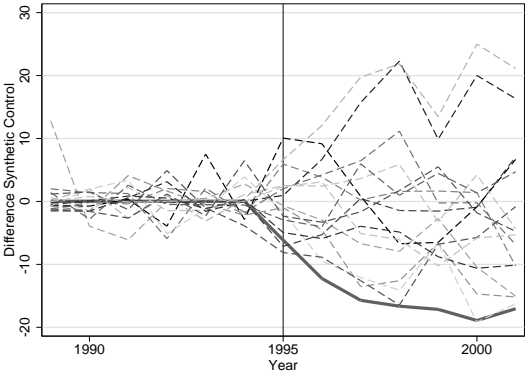

(b) Inference

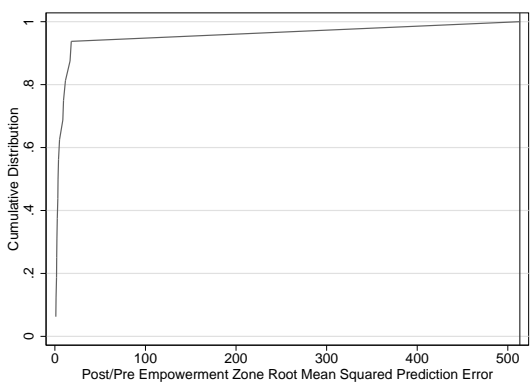

(d) Root Mean Sqared Error

Source: Author's estimation of equation (2) in the text, using the full sample of EZs and the limited sample of controls (Busso et al. 2013), excluding controls from cities with populations less than 100,000 or with less than 10 census tracts in the original application zone. Panel (a) provides estimates of the synthetic control method using EZ as the treatment. Panel (b) provides estimates of the effect of EZ status, systematically assigning EZ status to the actual EZ (the solid line) and all control zones (the dotted lines). Panel (c) provides the cumulative distribution of average treatment effects using estimates from the full inference sample, with a vertical line showing the average treatment effect for the actual EZ. Panel (d) provides the cumulative distribution of the ratio of post- to pre-root mean squared prediction error for the full inference sample, with a vertical line showing the value for the actual EZ. 
Figure 4: The Effect of Empowerment Zone Status on Birth Weight by Quantile

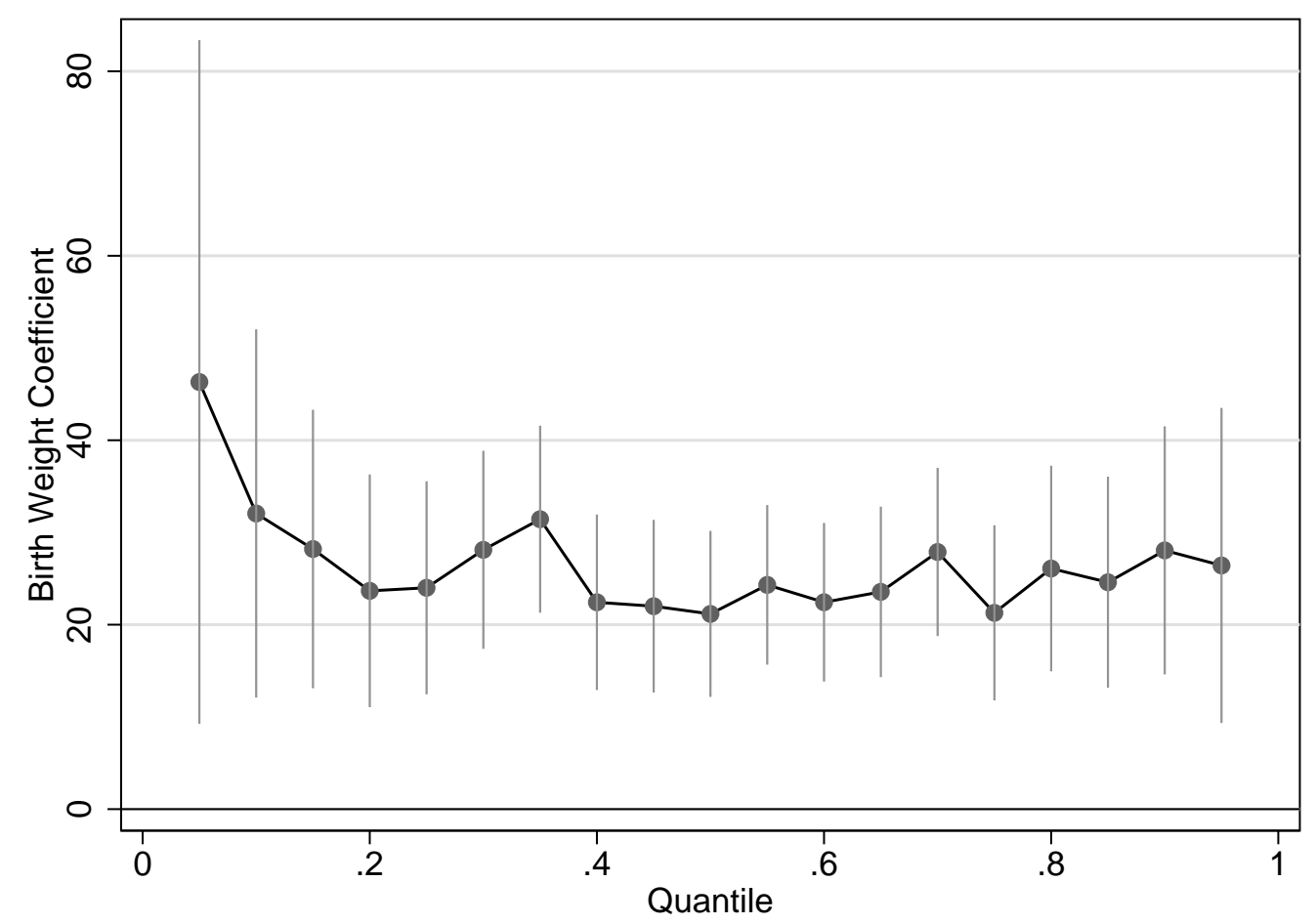

Source: This figure presents results of separate unconditional quantile regressions (Firpo et al. 2009) for every fifth percentile of the birth weight distribution. It uses the full sample of EZs and the limited sample of controls (Busso et al. 2013), excluding controls from cities with populations less than 100,000 or with less than 10 census tracts in the original application zone. 
Table 1: Unadjusted Difference-in-Differences Comparing Demographic Characteristics of Mothers by EZ status and Time

\begin{tabular}{|c|c|c|c|c|c|c|c|}
\hline & \multicolumn{3}{|c|}{ Empowerment Zones } & \multicolumn{3}{|c|}{ Contro Zones } & \multirow[b]{2}{*}{ D-in-D } \\
\hline & Pre & Post & Diff & Pre & Post & Diff & \\
\hline \multicolumn{8}{|c|}{ Panel A. Dependent Variables } \\
\hline Fertility Rates & $\begin{array}{c}117.4 \\
(18.55)\end{array}$ & $\begin{array}{c}83.19 \\
(11.14)\end{array}$ & $\begin{array}{l}-34.2^{* * *} \\
(5.996)\end{array}$ & $\begin{array}{c}94.99 \\
(16.70)\end{array}$ & $\begin{array}{c}80.74 \\
(20.51)\end{array}$ & $\begin{array}{r}-14.3^{* * *} \\
(2.538)\end{array}$ & $\begin{array}{l}-20.0^{* * *} \\
(5.608)\end{array}$ \\
\hline $\begin{array}{l}\text { Birth Weight } \\
\text { (BWT) }\end{array}$ & $\begin{array}{l}3138.9 \\
(627.7)\end{array}$ & $\begin{array}{l}3182.1 \\
(625.5)\end{array}$ & $\begin{array}{l}43.2^{*} \\
(17.7)\end{array}$ & $\begin{array}{l}209.4 \\
593.6)\end{array}$ & $\begin{array}{l}3219.2 \\
(592.3)\end{array}$ & $\begin{array}{l}9.791 \\
(11.5)\end{array}$ & $\begin{array}{c}33.4 \\
(18.7)\end{array}$ \\
\hline $\begin{array}{r}\text { Low B } \\
(<25\end{array}$ & $\begin{array}{c}0.123 \\
(0.328)\end{array}$ & $\begin{array}{c}0.106 \\
(0.308)\end{array}$ & $\begin{array}{l}-0.016^{*} \\
(0.007)\end{array}$ & $\begin{array}{l}0.0919 \\
(0.289)\end{array}$ & $\begin{array}{l}0.0882 \\
(0.284)\end{array}$ & $\begin{array}{l}-0.004 \\
(0.003)\end{array}$ & \\
\hline $\begin{array}{l}\text { Very Low BWT } \\
(<1500 \mathrm{~g})\end{array}$ & $\begin{array}{l}0.0218 \\
(0.146)\end{array}$ & $\begin{array}{l}0.0215 \\
(0.145)\end{array}$ & $\begin{array}{l}-0.000 \\
(0.002)\end{array}$ & $\begin{array}{l}0.0159 \\
(0.125)\end{array}$ & $\begin{array}{l}0.0160 \\
(0.126)\end{array}$ & $\begin{array}{c}0.000 \\
(0.001)\end{array}$ & \\
\hline $\begin{array}{l}\text { Full-term (37+ } \\
\text { Weeks) }\end{array}$ & $\begin{array}{c}0.867 \\
(0.339)\end{array}$ & $\begin{array}{c}0.881 \\
(0.324)\end{array}$ & $\begin{array}{c}0.014 \\
(0.008)\end{array}$ & $\begin{array}{c}0.891 \\
(0.311)\end{array}$ & $\begin{array}{c}0.889 \\
(0.314)\end{array}$ & $\begin{array}{l}-0.002 \\
(0.004)\end{array}$ & $\begin{array}{l}0.016^{*} \\
(0.008)\end{array}$ \\
\hline \multicolumn{8}{|c|}{ Panel B. Individual-Level Characteristics } \\
\hline Child Male & 0.509 & 0.509 & $(0.000)$ & 459 & 0.511 & 0.05 & \\
\hline $\mathrm{Ge}$ & $(0.500)$ & $(0$ & $(0$. & $(0.498)$ & $(0.500)$ & 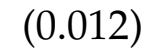 & \\
\hline Mot & $\begin{array}{l}0.0367 \\
(0.188)\end{array}$ & & $\begin{array}{l}-0.003 \\
(0.007)\end{array}$ & $\begin{array}{c}0.115 \\
(0.319)\end{array}$ & $\begin{array}{c}0.106 \\
(0.308)\end{array}$ & $\begin{array}{l}-0.008^{*} \\
(0.004)\end{array}$ & \\
\hline lot & $\begin{array}{c}0.592 \\
(0.491)\end{array}$ & $\begin{array}{c}0.546 \\
(0.498)\end{array}$ & $\begin{array}{c}-0.046^{* * * *} \\
(0.001)\end{array}$ & $\begin{array}{c}0.381 \\
(0.486)\end{array}$ & $\begin{array}{c}0.332 \\
(0.471)\end{array}$ & $\begin{array}{l}-0.049^{* *} \\
(0.016)\end{array}$ & \\
\hline $\begin{array}{r}\text { Motl } \\
\text { Ra }\end{array}$ & $\begin{array}{c}0.007 \\
(0.083)\end{array}$ & $\begin{array}{c}0.009 \\
(0.096)\end{array}$ & $\begin{array}{c}0.002 \\
(0.003)\end{array}$ & $\begin{array}{c}0.015 \\
(0.121)\end{array}$ & $\begin{array}{c}0.015 \\
(0.119)\end{array}$ & $\begin{array}{l}-0.000 \\
(0.001)\end{array}$ & $\begin{array}{c}0.003 \\
(0.003)\end{array}$ \\
\hline $\begin{array}{l}\text { Mother } \\
\text { Hispar }\end{array}$ & $\begin{array}{c}0.365 \\
(0.481)\end{array}$ & $\begin{array}{c}0.410 \\
(0.492)\end{array}$ & $\begin{array}{c}0.045^{* * *} \\
(0.008)\end{array}$ & & $\begin{array}{c}0.547 \\
(0.498)\end{array}$ & $\begin{array}{c}0.058^{* * *} \\
(0.018)\end{array}$ & \\
\hline Mom & $\begin{array}{c}0.489 \\
(0.500)\end{array}$ & $\begin{array}{c}0.525 \\
(0.499)\end{array}$ & $\begin{array}{c}0.036^{* * *} \\
(0.011)\end{array}$ & $\begin{array}{c}0.458 \\
(0.498)\end{array}$ & $\begin{array}{c}0.475 \\
(0.499)\end{array}$ & $\begin{array}{c}0.016 \\
(0.009)\end{array}$ & $\begin{array}{c}0.019 \\
(0.013)\end{array}$ \\
\hline $\begin{array}{l}\text { Mom } \\
\text { Coll }\end{array}$ & & $\begin{array}{c}0.205 \\
(0.404)\end{array}$ & $\begin{array}{l}0.045^{* *} \\
(0.015)\end{array}$ & & $\begin{array}{c}0.161 \\
(0.367)\end{array}$ & $\begin{array}{c}0.023^{* * *} \\
(0.005)\end{array}$ & \\
\hline ollege & $\begin{array}{l}0.0381 \\
(0.191)\end{array}$ & $\begin{array}{l}0.0560 \\
(0.230)\end{array}$ & $\begin{array}{c}0.018 \\
(0.009)\end{array}$ & $\begin{array}{l}0.0327 \\
(0.178)\end{array}$ & $\begin{array}{l}0.0457 \\
(0.209)\end{array}$ & $\begin{array}{c}0.013^{* * *} \\
(0.003)\end{array}$ & $\begin{array}{c}0.005 \\
(0.008)\end{array}$ \\
\hline Mom Grad & $\begin{array}{l}0.0129 \\
(0.113)\end{array}$ & $\begin{array}{l}0.0205 \\
(0.142)\end{array}$ & $\begin{array}{c}0.008 \\
(0.006)\end{array}$ & $\begin{array}{l}0.0113 \\
(0.106)\end{array}$ & $\begin{array}{l}0.0170 \\
(0.129)\end{array}$ & $\begin{array}{c}0.006^{* * *} \\
(0.002)\end{array}$ & $\begin{array}{c}0.002 \\
(0.005)\end{array}$ \\
\hline Mother Age & $\begin{array}{c}24.72 \\
(6.129)\end{array}$ & $\begin{array}{c}25.25 \\
(6.364)\end{array}$ & $\begin{array}{c}0.531^{* * *} \\
(0.109)\end{array}$ & $\begin{array}{c}23.99 \\
(5.957)\end{array}$ & $\begin{array}{c}24.22 \\
(5.954)\end{array}$ & $\begin{array}{l}0.232^{*} \\
(0.101)\end{array}$ & $\begin{array}{l}0.299^{*} \\
(0.136)\end{array}$ \\
\hline & Tract- & evel Ch & acteristics & & & & \\
\hline bservations & 69043 & 59267 & 128310 & 118099 & 121698 & 239797 & 368094 \\
\hline
\end{tabular}


Table 1: (Continued)

\begin{tabular}{lccccccc}
\hline & \multicolumn{3}{c}{ Empowerment Zones } & \multicolumn{3}{c}{ Control Zones } \\
& Pre & Post & Diff & Pre & Post & Diff & D-in-D \\
\hline Male & 0.464 & 0.468 & 0.004 & 0.489 & 0.491 & 0.002 & 0.002 \\
& $(0.083)$ & $(0.065)$ & $(0.003)$ & $(0.067)$ & $(0.066)$ & $(0.003)$ & $(0.004)$ \\
White & 0.119 & 0.128 & 0.009 & 0.384 & 0.393 & 0.009 & 0.000 \\
& $(0.177)$ & $(0.168)$ & $(0.013)$ & $(0.282)$ & $(0.265)$ & $(0.011)$ & $(0.015)$ \\
Black & 0.701 & 0.676 & -0.026 & 0.468 & 0.443 & $-0.025^{*}$ & -0.001 \\
& $(0.362)$ & $(0.362)$ & $(0.023)$ & $(0.361)$ & $(0.347)$ & $(0.010)$ & $(0.022)$ \\
Other Race & 0.177 & 0.196 & 0.019 & 0.145 & 0.163 & $0.018^{* * *}$ & 0.001 \\
& $(0.237)$ & $(0.233)$ & $(0.011)$ & $(0.173)$ & $(0.163)$ & $(0.004)$ & $(0.010)$ \\
Hispanic & 0.257 & 0.276 & $0.019^{*}$ & 0.289 & 0.313 & $0.023^{* * *}$ & -0.005 \\
& $(0.329)$ & $(0.334)$ & $(0.008)$ & $(0.355)$ & $(0.358)$ & $(0.005)$ & $(0.008)$ \\
HS Grad & 0.464 & 0.549 & $0.085^{* * *}$ & 0.505 & 0.570 & $0.065^{* * *}$ & $0.019^{*}$ \\
& $(0.137)$ & $(0.134)$ & $(0.005)$ & $(0.150)$ & $(0.162)$ & $(0.007)$ & $(0.008)$ \\
Some College & 0.160 & 0.202 & $0.042^{* * *}$ & 0.171 & 0.190 & $0.020^{* * *}$ & $0.023^{* * *}$ \\
& $(0.068)$ & $(0.086)$ & $(0.002)$ & $(0.073)$ & $(0.067)$ & $(0.004)$ & $(0.005)$ \\
College & 0.065 & 0.091 & $0.026^{* * *}$ & 0.083 & 0.107 & $0.024^{* * *}$ & 0.002 \\
Grad & $(0.060)$ & $(0.074)$ & $(0.002)$ & $(0.082)$ & $(0.099)$ & $(0.005)$ & $(0.005)$ \\
Median HH & 19713 & 23577 & $3865^{* *}$ & 20822 & 24209 & $3387^{* * *}$ & 478 \\
Income & $(9062)$ & $(10557)$ & $(1327)$ & $(8202)$ & $(9401)$ & $(442)$ & $(1198)$ \\
Percent Vacant & 0.154 & 0.162 & 0.008 & 0.166 & 0.143 & $-0.023^{*}$ & $0.031^{*}$ \\
Housing & $(0.107)$ & $(0.111)$ & $(0.009)$ & $(0.085)$ & $(0.071)$ & $(0.011)$ & $(0.013)$ \\
Percent Below & 0.476 & 0.423 & $-0.053^{* * *}$ & 0.436 & 0.388 & $-0.047^{* * *}$ & -0.006 \\
Poverty & $(0.163)$ & $(0.145)$ & $(0.014)$ & $(0.135)$ & $(0.126)$ & $(0.006)$ & $(0.014)$ \\
\hline Observations & 69043 & 59267 & 128310 & 118099 & 121698 & 239797 & 368094
\end{tabular}

Source: Vital statistics data from Colorado, Florida, Illinois, Kentucky, New York, Ohio, Oregon, Pennsylvania, and Texas. The analysis sample is composed of babies born to mothers living in empowerment zones or control areas, which are areas that applied for, but did receive, empowerment zone status or areas that received empowerment zone status in a later round. The limited sample of controls (Busso et al. 2013) is used, excluding controls from cities with populations less than 100,000 or with less than 10 census tracts in the original application zone. ${ }^{* * *}$ indicates significance at the $0.1 \%$ level, ${ }^{* *}$ indicates significance at the $1 \%$ level, * indicates significance at the $5 \%$ level. 
Table 2: The Effect of Empowerment Zone Status on Birth Weight

\begin{tabular}{cccccc}
\hline & $\begin{array}{c}\text { Fertility } \\
\text { per } \\
1,000\end{array}$ & $\begin{array}{c}\text { Birth } \\
\text { Weight } \\
\text { (Grams) }\end{array}$ & $\begin{array}{c}\text { Low } \\
\text { Birth } \\
\text { Weight }\end{array}$ & $\begin{array}{c}\text { Very Low } \\
\text { Birth } \\
\text { Weight }\end{array}$ & $\begin{array}{c}\text { Full-term } \\
37+ \\
\text { Weeks }\end{array}$ \\
\hline Panel A. Cross City Control Zones \\
(1) Difference-in- & $-9.6^{* * *}$ & $25.5^{* * *}$ & $-0.008^{* * *}$ & 0.000 & $0.009^{* *}$ \\
Differences & $(2.914)$ & $(8.290)$ & $(0.003)$ & $(0.001)$ & $(0.004)$ \\
Obs & 234 & 360526 & 360526 & 360526 & 354477 \\
Dep Var Mean & 89.3 & 3197.9 & 0.098 & 0.017 & 0.883 \\
\hline (2) Synthetic & $-14.86^{*+}$ & 17.90 & $-0.013^{+}$ & 0.001 & $0.018^{+}$ \\
Controls & $(0.063)$ & $(0.250)$ & $(0.188)$ & $(0.563)$ & $(0.875)$ \\
& $(0.000)$ & $(0.125)$ & $(0.000)$ & $(0.500)$ & $(0.063)$ \\
\hline Panel B. Same City Control Zones & & & \\
(3) Difference-in- & $-11.4^{* * *}$ & 12.8 & -0.006 & 0.001 & 0.004 \\
Differences & $(3.425)$ & $(11.329)$ & $(0.004)$ & $(0.001)$ & $(0.004)$ \\
Obs & 1285 & 938829 & 938829 & 938829 & 923646 \\
Dep Var Mean & 79.5 & 3197.5 & 0.101 & 0.018 & 0.891 \\
\hline (4) Synthetic & $-10.2^{+}$ & 18.7 & -0.007 & 0.0006 & 0.006 \\
Controls & $(0.179)$ & $(0.262)$ & $(0.238)$ & $(0.571)$ & $(0.667)$ \\
& $(0.036)$ & $(0.488)$ & $(0.452)$ & $(0.452)$ & $(0.440)$ \\
\hline
\end{tabular}

Source: Author's estimation of equation (1) and (2) in the text using all 3 empowerment zones and control zones listed in the panel. Data are from vital statistics data from Colorado, Florida, Illinois, Kentucky, New York, Ohio, Oregon, Pennsylvania, and Texas. In Panel A, the analysis sample is composed of babies born to mothers living in empowerment zones or control areas, which are areas that applied for, but did receive, empowerment zone status or areas that received empowerment zone status in a later round. Panel B uses a control sample of babies born to mothers living in census tracts in the same city as EZs with poverty rates above $20 \%$. Each cell in the table comes from a separate regression. Estimates include controls for mother's race and ethnicity, child's gender, tract level demographic characteristics including race and ethnicity, educational attainment, median household income, vacancy rates, and poverty rates, and year and tract level fixed effects. Fertility rate regressions are performed at the aggregated EZ program level. Standard errors clustered at the zone level are in parentheses. ${ }^{* * *}$ indicates significance at the $1 \%$ level, ${ }^{* *}$ indicates significance at the $5 \%$ level, * indicates significance at the $10 \%$ level. Numbers in parentheses in rows (2) and (4) represent the implied p value of the average treatment effect (ATE), and the implied $\mathrm{p}$ value of the ratio of the post to pre root mean squared prediction error (MSPE). * indicates significance at the 10\% level using ATE, + indicates significance at the $10 \%$ level using MSPE. 
Table 3: The Effect of Empowerment Zone Status on Maternal Outcomes: Difference-in-Differences Results

\begin{tabular}{cccc}
\hline & $\begin{array}{c}\text { No } \\
\text { Prenatal }\end{array}$ & $\begin{array}{c}\text { Month } \\
\text { Prenatal }\end{array}$ & Smoke \\
\hline \multicolumn{2}{l}{ Panel A. Cross City Control Zones } & & \\
\hline Difference-in- & -0.018 & -0.157 & $0.020^{* *}$ \\
$\quad$ Differences & $(0.016)$ & $(0.176)$ & $(0.009)$ \\
Obs & 349759 & 344051 & 354643 \\
Dep Var Mean & 0.061 & 3.231 & 0.148 \\
\hline Panel B. Same City Control Zones & & \\
Difference-in- & 0.001 & 0.049 & -0.005 \\
$\quad$ Differences & $(0.013)$ & $(0.159)$ & $(0.011)$ \\
Obs & 885761 & 842673 & 934350 \\
Dep Var Mean & 0.054 & 3.875 & 0.105 \\
\hline
\end{tabular}

Source: Author's estimation of equation (1) in the text using all 3 empowerment zones and control zones listed in the panel. In Panel A, the analysis sample consists of babies born to mothers living in empowerment zones or control areas, which are areas that applied for, but did receive, empowerment zone status or areas that received empowerment zone status in a later round. Panel B uses a control sample of babies born to mothers living in census tracts in the same city as EZs with poverty rates above $20 \%$. Data are from vital statistics data from Colorado, Florida, Illinois, Kentucky, New York, Ohio, Oregon, Pennsylvania, and Texas. The analysis sample is composed of babies born to mothers living in empowerment zones or control areas, which are areas that applied for, but did receive, empowerment zone status or areas that received empowerment zone status in a later round. Each cell in the table comes from a separate regression. No Prenatal denotes the mother did not receive prenatal care during pregnancy, Month Prenatal refers to the month a mother first received prenatal care, contingent on ever receiving such care, and Smoking refers to ever smoking during pregnancy. Estimates include controls for mother's race and ethnicity, child's gender, tract level demographic characteristics including race and ethnicity, educational attainment, median household income, vacancy rates, and poverty rates, and year and tract level fixed effects. Standard errors clustered at the program level are in parentheses: ${ }^{* * *}$ indicates significance at the $1 \%$ level, ${ }^{* *}$ indicates significance at the $5 \%$ level, ${ }^{*}$ indicates significance at the $10 \%$ level. 


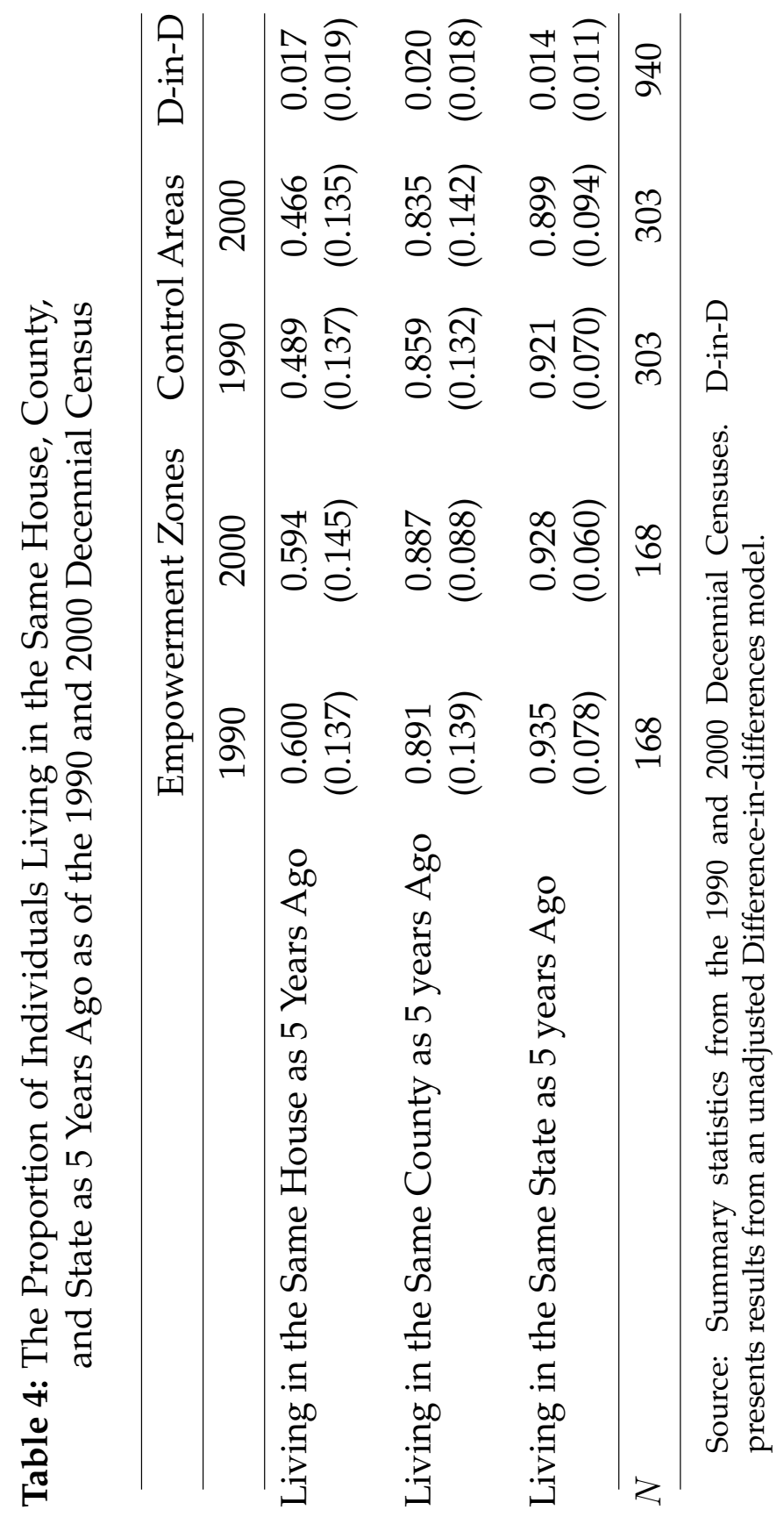


Table 5: The Effect of Empowerment Zone Status on Predicted Birth Outcomes Using 1990-1994 Data to Predict Outcomes

\begin{tabular}{|c|c|c|c|c|c|}
\hline & $\begin{array}{c}\text { Fertility } \\
\text { per } \\
1,000\end{array}$ & $\begin{array}{c}\text { Birth } \\
\text { Weight } \\
\text { (Grams) }\end{array}$ & $\begin{array}{c}\text { Low } \\
\text { Birth } \\
\text { Weight }\end{array}$ & $\begin{array}{l}\text { Very Low } \\
\text { Birth } \\
\text { Weight }\end{array}$ & $\begin{array}{c}\text { Full-term } \\
37+ \\
\text { Weeks }\end{array}$ \\
\hline \multicolumn{6}{|c|}{ Panel A. Chicago, New York, and Philadelphia Zones Compared to } \\
\hline \multirow[b]{2}{*}{ Predicted } & \multicolumn{2}{|c|}{ Control Zones } & & & \\
\hline & $\begin{array}{c}0.209 \\
(1.904)\end{array}$ & $\begin{array}{c}-4.259 \\
(4.037)\end{array}$ & $\begin{array}{c}0.001 \\
(0.001)\end{array}$ & $\begin{array}{c}0.0001 \\
(0.0002)\end{array}$ & $\begin{array}{c}-0.0001 \\
(0.001)\end{array}$ \\
\hline \multicolumn{5}{|c|}{ Panel B. Only Chicago Zones Compared to Control Zone } & \multirow[b]{2}{*}{$\begin{array}{l}-0.001 \\
(0.001)\end{array}$} \\
\hline Predicted & $\begin{array}{c}3.610^{* * *} \\
(1.105)\end{array}$ & $\begin{array}{c}-8.571^{* *} \\
(3.684)\end{array}$ & $\begin{array}{l}0.002^{* *} \\
(0.001)\end{array}$ & $\begin{array}{c}0.0003 \\
(0.0002)\end{array}$ & \\
\hline \multicolumn{6}{|c|}{ Panel C. Only New York Zones Compared to Control Zones } \\
\hline Predicted & $\begin{array}{c}-2.490^{* *} \\
(1.105)\end{array}$ & $\begin{array}{l}-6.780^{*} \\
(3.769)\end{array}$ & $\begin{array}{l}0.002^{*} \\
(0.001)\end{array}$ & $\begin{array}{c}0.0003 \\
(0.0002)\end{array}$ & $\begin{array}{c}-0.001 \\
(0.0008)\end{array}$ \\
\hline \multicolumn{6}{|c|}{ Panel D. Only Philadelphia Zones Compared to Control Zones } \\
\hline Predicted & $\begin{array}{c}-0.492 \\
(1.105)\end{array}$ & $\begin{array}{c}-11.00^{* * *} \\
(3.729)\end{array}$ & $\begin{array}{c}0.003^{* * *} \\
(0.001)\end{array}$ & $\begin{array}{l}0.0004^{*} \\
(0.0002)\end{array}$ & $\begin{array}{c}-0.002^{*} \\
(0.001) \\
\end{array}$ \\
\hline
\end{tabular}

Source: Author's estimation using predicted values of fertility rates calculated using demographically weighted 1990 national age-race fertility rates. Predicted values of birth outcomes calculated by regressing birth outcome on maternal demographic characteristics including race and ethnicity, educational attainment, and mothers age at the time of birth for 1989-1994. Predicted estimates come from regressing predicted outcomes on an indicator variable for whether the birth occurred in an EZ, the interaction of the variable EZ and post, an indicator for whether the baby was conceived in 1995 or later, and year fixed effects which subsume the variable post. I use all EZs and the limited sample of controls (Busso et al. 2013), excluding controls from cities with populations less than 100,000 or with less than 10 census tracts in the original application zone. Standard errors clustered at the program level are in parentheses: ${ }^{* * *}$ indicates significance at the $1 \%$ level, ${ }^{* *}$ indicates significance at the $5 \%$ level, ${ }^{*}$ indicates significance at the $10 \%$ level. 
Table 6: The Effect of Empowerment Zone Status on Fertility Rates by Age

\begin{tabular}{|c|c|c|c|c|c|c|}
\hline Age Range & $15-19$ & $20-24$ & $25-29$ & $30-34$ & $35-39$ & $40-44$ \\
\hline \multicolumn{7}{|c|}{ Panel A. Cross City Control Zones } \\
\hline $\begin{array}{r}\text { (1) Difference-in- } \\
\text { Differences }\end{array}$ & $\begin{array}{l}-1.6 \\
(4.6)\end{array}$ & $\begin{array}{c}-17.8^{*} \\
(9.4)\end{array}$ & $\begin{array}{c}-19.2^{* * *} \\
(4.1)\end{array}$ & $\begin{array}{l}-6.5^{* *} \\
(3.0)\end{array}$ & $\begin{array}{l}-2.9 \\
(1.9)\end{array}$ & $\begin{array}{l}-0.2 \\
(0.9)\end{array}$ \\
\hline Obs & 234 & & & & 234 & 234 \\
\hline Dep & 134.8 & & & & 34 & 8.1 \\
\hline$\%$ Change & -1.2 & & 10 & -9 . & -8.6 & -2.2 \\
\hline $\begin{array}{l}\text { (2) Synth } \\
\text { CoI }\end{array}$ & $\begin{array}{c}-17.4^{+} \\
(0.313) \\
(0.000)\end{array}$ & & & & & -0.7 \\
\hline \multicolumn{7}{|c|}{ Panel B. Same City Control Zones } \\
\hline $\begin{array}{r}\text { (3) Difference-in- } \\
\text { Differences }\end{array}$ & $\begin{array}{l}-16.7^{*} \\
(8.8)\end{array}$ & & $\begin{array}{c}-19.6^{* * *} \\
(5.0)\end{array}$ & $\begin{array}{c}-7.4^{* *} \\
(3.1)\end{array}$ & 0.3 & $\begin{array}{l}-0.9 \\
(0.6)\end{array}$ \\
\hline Obs & 1283 & & & 12 & 12 & 1284 \\
\hline ep V & 88.1 & & & & 36 & 8.2 \\
\hline$\%$ Change & -18.9 & -14.2 & -18.8 & -10.0 & 0.7 & -11.0 \\
\hline $\begin{array}{l}\text { 4) Synthetic } \\
\text { Controls }\end{array}$ & $\begin{array}{c}-25.7^{*} \\
(0.072) \\
(0.157)\end{array}$ & $\begin{array}{c}-22.3 \\
(0.107) \\
(0.131)\end{array}$ & $\begin{array}{c}-12.0 \\
(0.202) \\
(0.119)\end{array}$ & $\begin{array}{c}-17.1^{*} \\
(0.095) \\
(0.321)\end{array}$ & $\begin{array}{c}-0.9 \\
(0.476) \\
(0.381)\end{array}$ & $\begin{array}{c}-1.6 \\
(0.262) \\
(0.286)\end{array}$ \\
\hline
\end{tabular}

Source: Authors estimation of equation (1) in the text using all 3 empowerment zones and control zones listed in the panel. Data are from vital statistics data from Colorado, Florida, Illinois, Kentucky, New York, Ohio, Oregon, Pennsylvania, and Texas. The analysis sample is composed of fertility rates calculated as the number of babies born to mothers living in empowerment zones or control areas between the stated ages divided by the total population of women in these areas between those ages. In Panel A, the analysis sample is composed of babies born to mothers living in empowerment zones or control areas, which are areas that applied for, but did receive, empowerment zone status or areas that received empowerment zone status in a later round. Panel B uses a control sample of babies born to mothers living in census tracts in the same city as EZs with poverty rates above $20 \%$. Each cell in the table comes from a separate regression. All regressions are performed at the aggregated EZ program level. The estimates include zone-level controls for mother's age, race and ethnicity, high school graduate, some college, and college graduate, child's gender, and year fixed effects, overall zonelevel race and ethnicity, educational attainment, median household income, vacancy rates, and poverty rates, and program-level fixed effects. Standard errors clustered at the program level are in parentheses: ${ }^{* * *}$ indicates significance at the $1 \%$ level, ${ }^{* *}$ indicates significance at the $5 \%$ level, ${ }^{*}$ indicates significance at the $10 \%$ level. 
Table 7: The Effect of Empowerment Zone Status on Birth Weight: Difference-in-Differences Heterogeneous Treatment Effects

\begin{tabular}{|c|c|c|c|c|c|}
\hline & $\begin{array}{c}\text { Fertility } \\
\text { per } \\
1,000\end{array}$ & $\begin{array}{c}\text { Birth } \\
\text { Weight } \\
\text { (Grams) }\end{array}$ & $\begin{array}{c}\text { Low } \\
\text { Birth } \\
\text { Weight }\end{array}$ & $\begin{array}{c}\text { Very Low } \\
\text { Birth } \\
\text { Weight }\end{array}$ & $\begin{array}{c}\text { Full-term } \\
37+ \\
\text { Weeks }\end{array}$ \\
\hline \multicolumn{6}{|c|}{ Panel A. High School Diploma or Less } \\
\hline \multicolumn{2}{|l|}{ All EZs (N=302760) } & $\begin{array}{l}23.4^{* * *} \\
(9.042)\end{array}$ & $\begin{array}{c}-0.009^{* *} \\
(0.004)\end{array}$ & $\begin{array}{c}0.000 \\
(0.001)\end{array}$ & $\begin{array}{l}0.009^{*} \\
(0.005)\end{array}$ \\
\hline Dep Var Mean & & 3188.0 & 0.100 & 0.017 & 0.881 \\
\hline \multicolumn{6}{|c|}{ Panel B. More Than a High School Diploma } \\
\hline \multicolumn{2}{|c|}{ All EZs (N=57766) } & $\begin{array}{l}43.1^{* * *} \\
(7.753)\end{array}$ & $\begin{array}{l}-0.003 \\
(0.003)\end{array}$ & $\begin{array}{c}0.002 \\
(0.002)\end{array}$ & $\begin{array}{c}0.011^{* * *} \\
(0.003)\end{array}$ \\
\hline Dep Var Mean & & 3249.9 & 0.085 & 0.017 & 0.895 \\
\hline \multicolumn{6}{|l|}{ Panel C. Black Only } \\
\hline All EZs & $\begin{array}{l}-11.1^{* *} \\
(4.510)\end{array}$ & $\begin{array}{c}35.3^{* * *} \\
(13.1)\end{array}$ & $\begin{array}{c}-0.013^{* *} \\
(0.007)\end{array}$ & $\begin{array}{c}-0.000 \\
(0.002)\end{array}$ & $\begin{array}{c}0.018^{*} \\
(0.010)\end{array}$ \\
\hline Obs & 234 & 155288 & 155288 & 155288 & 152832 \\
\hline Dep Var Mean & 101.2 & 3073.1 & 0.140 & 0.026 & 0.846 \\
\hline \multicolumn{6}{|c|}{ Panel D. Hispanic Only } \\
\hline All EZs & $\begin{array}{c}-2.1 \\
(16.1)\end{array}$ & $\begin{array}{c}26.4^{* * *} \\
(9.2)\end{array}$ & $\begin{array}{c}-0.005^{* *} \\
(0.002)\end{array}$ & $\begin{array}{c}0.000 \\
(0.001)\end{array}$ & $\begin{array}{c}-0.001 \\
(0.002)\end{array}$ \\
\hline Obs & 232 & 170883 & 170883 & 170883 & 167519 \\
\hline Dep Var Mean & 115.4 & 3291.9 & 0.064 & 0.010 & 0.916 \\
\hline \multicolumn{6}{|l|}{ Panel E. White Only } \\
\hline All EZs & $\begin{array}{c}-7.5 \\
(12.3)\end{array}$ & $\begin{array}{l}-17.7 \\
(18.8)\end{array}$ & $\begin{array}{c}-0.004 \\
(0.007)\end{array}$ & $\begin{array}{c}0.004 \\
(0.003)\end{array}$ & $\begin{array}{c}0.008 \\
(0.008)\end{array}$ \\
\hline Obs & 234 & 30457 & 30457 & 30457 & 30288 \\
\hline Dep Var Mean & 68.5 & 3302.1 & 0.076 & 0.012 & 0.906 \\
\hline
\end{tabular}

Source: Author's estimation of equation (1) in the text using all 3 empowerment zones and control zones listed in the panel. Data are from vital statistics data from Colorado, Florida, Illinois, Kentucky, New York, Ohio, Oregon, Pennsylvania, and Texas. The analysis sample is composed of babies born to mothers living in empowerment zones or control areas, which are areas that applied for, but did receive, empowerment zone status or areas that received empowerment zone status in a later round. Each cell in the table comes from a separate regression. The estimates include controls for mother's race and ethnicity, child's gender, and year fixed effects, controls for tract level demographic characteristics including race and ethnicity, educational attainment, median household income, vacancy rates, and poverty rates, and tract level fixed effects. Fertility rate regressions are performed at the aggregated EZ program level. Standard errors clustered at the program level are in parentheses: ${ }^{* * *}$ indicates significance at the $1 \%$ level, ${ }^{* *}$ indicates significance at the $5 \%$ level, ${ }^{*}$ indicates significance at the $10 \%$ level. 


\section{**** For Online Publication ***}

\section{Appendix A.}

\section{A.1. Heterogeneous Treatment Effects by Zone}

The overall average treatment effects of the EZ program masks considerable heterogeneous treatment effects of this program in each EZ. In this section, I present results from estimates that limit the analysis sample to comparisons of each EZ individually to a full set of zones that applied for but did not receive or received the EZ program at a later point in time, estimating both difference-in-differences and synthetic control models. I also estimate these models using same city control areas. However, this sample differs from the same city control sample used in section 6.1 in that I only include control areas from the specific EZ city. For example, the analysis of the Chicago EZ uses a control group composed only of Chicago control areas.

Importantly, for each EZ individually, the results are robust to both difference-in-differences and synthetic control methods and to alternate, same city control groups. However the results vary substantially by zone, which I discuss in more detail below.

\section{A.1.1. Chicago}

Estimates using only the Chicago EZ, shown in Appendix Table 7, provide substantively similar results to the main estimates using all EZs. Fertility rates in the Chicago EZ decrease substantially compared to control zones using both methods for each control group. These point estimates are statistically significant in all cases. For birth outcomes, the Chicago EZ increases birth weight relative to control areas by between 8 and 27 grams. These results are statistically significant in all cases. Low birth weight rates decrease by between 0.6 and 1.5 percentage points in the Chicago EZ compared to control areas with all estimates, except the synthetic control result in row (2), exhibiting statistical significance. In Panel A of Appendix Figure 8, I find that distributional effects of the EZ program 
using unconditional quantile regressions are substantively similar to the results using all EZs shown in Figure 4. ${ }^{1}$

\section{A.1.2. New York City}

The New York EZ exhibits the smallest decreases in fertility rates of the three EZs, but the largest improvements in birth outcomes as shown in Appendix Table 8. The EZ decreases fertility rates by between 4 and 6 births per 1,000. These results are statistically significant in 2 of the 4 specifications. Birth weight in the New York EZ increases by between 43 and 45 grams compared to the main control group using both difference-in-differences and synthetic control methods, but increases between 13 and 27 grams compared to a same city control group. These effects are statistically significant in all cases except the same city synthetic control method in row (4). The EZ program decreases low birth weight rates by between 0.5 and 1.8 percentage points compared to control areas. The results are consistent and fairly robust across methods, with the only exception an attenuated point estimate for the same city synthetic control method. Babies born in the New York EZ were 1.6 percentage points more likely to be of full-term. Appendix Figure 8, Panel B shows similar distributional effects for New York compared to the pooled results shown in Figure 4.

\section{A.1.3. Philadelphia}

Fertility rates for Philadelphia are of a similar magnitude to those of the main results, as shown in Appendix Table 9. However, birth outcomes worsen in the Philadelphia EZ, the only EZ that exhibits this effect. Despite persistent evidence of increases in birth weight in the Philadelphia EZ, low and very low birth weight increase substantially compared to both control groups. The magnitude of these effects is between a 0.5 and 1.2 percentage point increase in very low birth weight and is robust to all control groups and model specifications. Distributional effects for Philadelphia, in Appendix Figure 8, Panel C, similarly

\footnotetext{
${ }^{1}$ This is the same specification as in Figure 4, but performed separately by EZ.
} 
exhibit opposite results compared to each of the other EZs and the overall EZ effects. They imply worse outcomes for those in the lowest quantiles of the birth weight distribution.

\section{A.1.4. Potential Explanations for Heterogeneity by Empowerment Zones}

The nature of the EZ program provided each zone with a large degree of autonomy over whether to focus resources on economic opportunities or social and community development, and how and when to spend the program resources. The disbursement of funds differed greatly by city both in terms of time and goals.

Nearly two-thirds of the New York EZ's projects focused on economic activity, while this number was closer to one-third for both Chicago and Philadelphia. Meanwhile, nearly two-thirds of projects in Chicago and Philadelphia focused on community development (Government Accountability Office 2006). Projects intended to improve public housing were a substantial part of the Chicago and Philadelphia EZs, but were not a major part of the New York EZ. On the other hand, workforce development was a major aim of the EZ program in New York and Chicago, but less so in Philadelphia (Hebert et al. 2001).

The Philadelphia EZ had significant delays in commencing infrastructure projects. The reasons for these delays include high staff turnover, community activist dissatisfaction, and mayoral interference (Gittell et al. 2001, Hebert et al. 2001). While similar complaints have been made against other EZs, these issues were particularly pronounced in the Philadelphia EZ. Yet, despite these delays, each of these 3 EZs had spent a similar percent of the total amount of block grants received by 2000 . Chicago had spent approximately $\$ 62$ million, while New York 
had spent approximately $\$ 48$ million, ${ }^{2}$ and Philadelphia spent $\$ 50$ million. $^{3}$

However, it is unclear how much of these funds had been spent on completed projects that could provide tangible benefits to city residents. Despite these various differences in program implementation, no clear explanation for these differences in outcomes emerges.

${ }^{2}$ New York spent an additional $\$ 48$ million in matching funds from both the city and state by this time for a total of $\$ 144$ million in EZ funds spent on infrastructure projects.

${ }^{3}$ These numbers come from the US Housing and Urban Development Annual Performance Measurement System (available at http://www5.hud.gov/urban/perms/perms.asp). 


\section{Appendix References}

Gittell, Marilyn. "Empowerment Zones: An Opportunity Missed: a Six-city Comparative Study." The Howard Samuels State Management and Policy Centre, The Graduate School and the University Centre of the City University of New York (2001).

Government Accountability Office. 2006. "Empowerment Zone and Enterprise Community Program: Improvements Occurred in Communities, But The Effect of The Program Is Unclear.” Report \# 06-727. Washington, DC: GAO.

Hebert, Scott, Avis Vidal, Greg Mills, Franklin James, and Debbie Gruenstein. 2011. "Interim Assessment of the Empowerment Zones and Enterprise Communities (EZ/EC) Program: A Progress Report." Washington, DC: US Department of Housing and Urban Development, Office of Policy Development and Research at http://www.huduser.org/Publications/pdf/ezec_report.pdf.

US Department of Housing and Urban Development. 2000. "Empowerment Zones/Enterprise Communities Annual Report: Chicago, Illinois Empowerment Zone," RC/EZ/EC Performance Measurement System: accessed at http://www5.hud.gov/urban/perms/perms.asp, on October 27, 2014. . 2000. "Empowerment Zones/Enterprise Communities Annual Report: New York, New York Empowerment Zone," RC/EZ/EC Performance Measurement System: accessed at http://www5.hud.gov/urban/perms/perms.asp, on October 27, 2014. . 2000. "Empowerment Zones/Enterprise Communities Annual Report:

Philadelphia, Pennsylvania Empowerment Zone," RC/EZ/EC Performance Measurement System: accessed at http://www5.hud.gov/urban/perms/perms.asp, on October 27, 2014. 
*** For Online Publication *** 


\section{Figure A1: Fertility and Birth Outcomes Separately by Empowerment Zone Status: Chicago EZ Only}

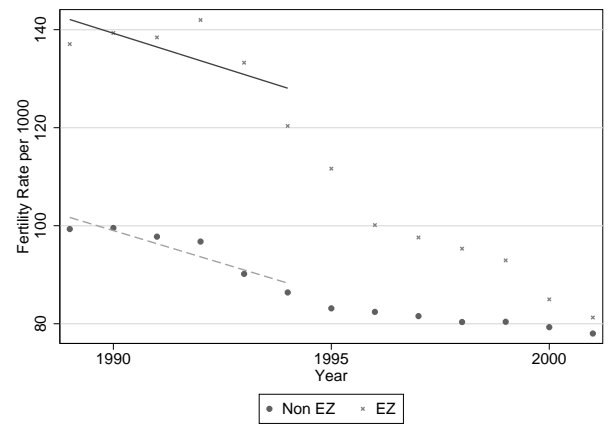

(a) Fertility

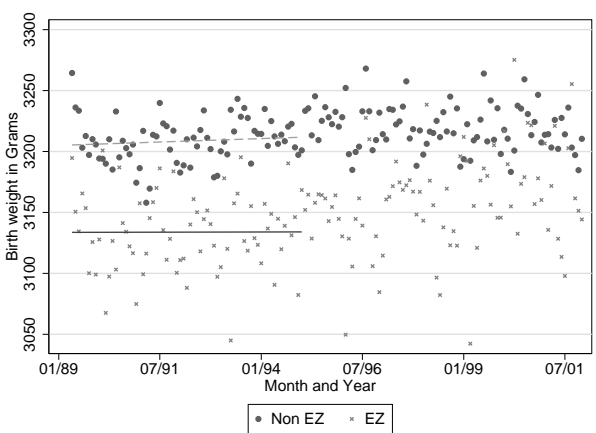

(b) Birth Weight

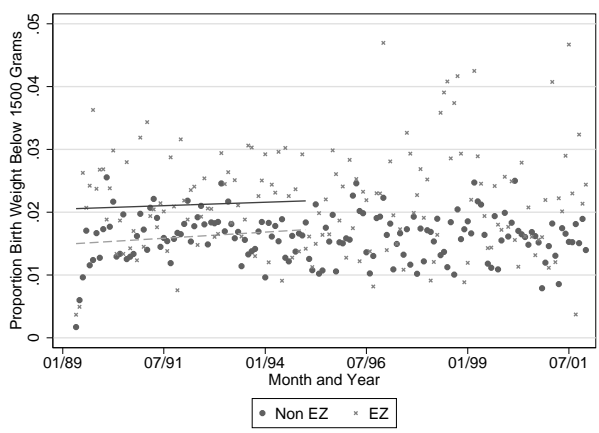

(d) Very Low Birth Weight

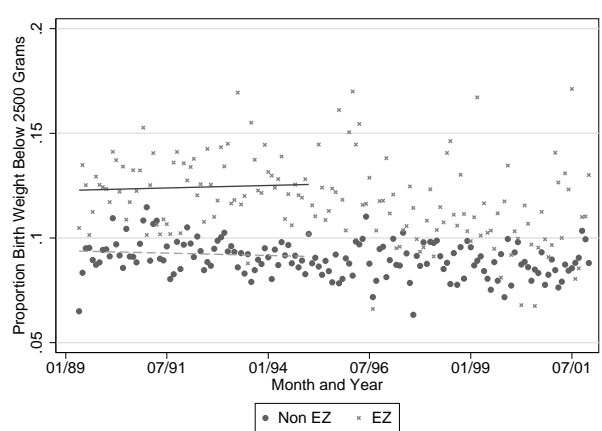

(c) Low Birth Weight

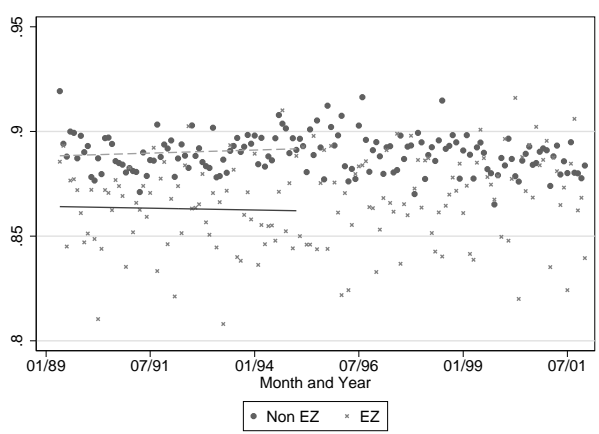

(e) Full-term

Source: Fertility and birth outcomes collapsed by year or month, with linear trend lines for both the pre- and post- empowerment zone periods. Chicago EZ compared to the limited sample of controls (Busso et al. 2013), excluding controls from cities with populations less than 100,000 or with less than 10 census tracts in the original application zone. 


\section{Figure A2: Fertility and Birth Outcomes Separately by Empowerment Zone Status: New York EZ Only}

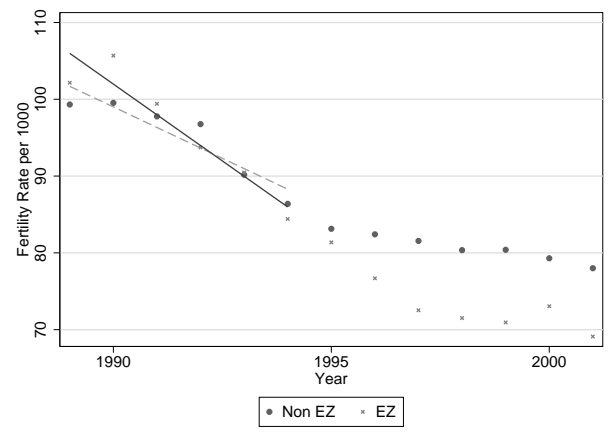

(a) Fertility

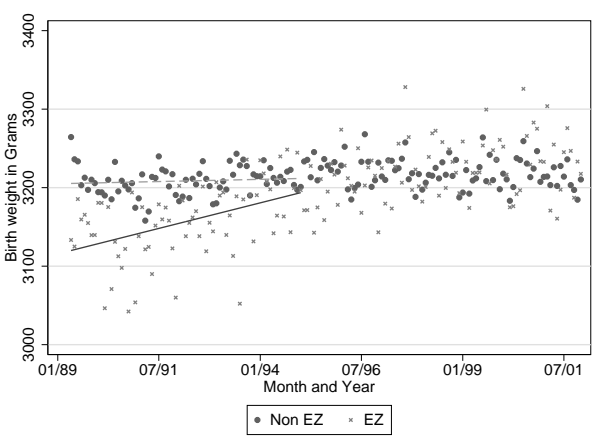

(b) Birth Weight

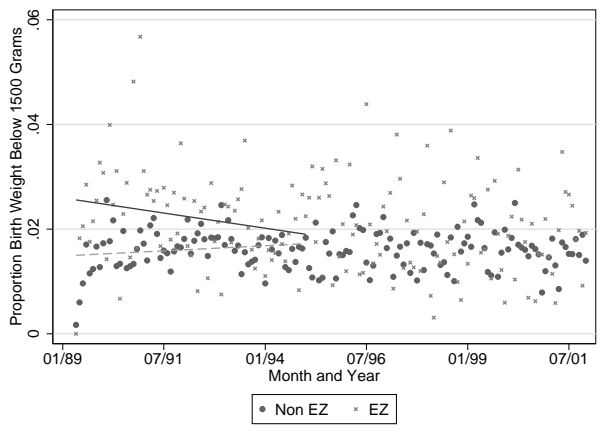

(d) Very Low Birth Weight

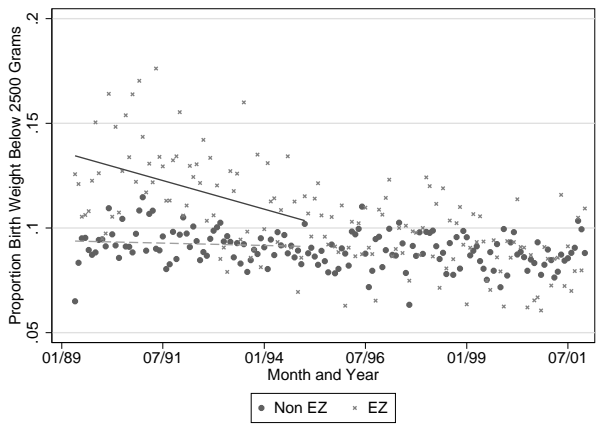

(c) Low Birth Weight

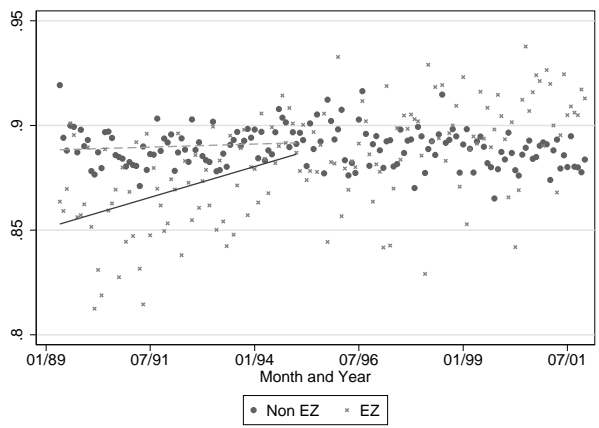

(e) Full-term

Source: Fertility and birth outcomes collapsed by year or month, with linear trend lines for both the pre- and post- empowerment zone periods. New York EZ compared to the limited sample of controls (Busso et al. 2013), excluding controls from cities with populations less than 100,000 or with less than 10 census tracts in the original application zone. 


\section{Figure A3: Fertility and Birth Outcomes Separately by Empowerment Zone Status: Philadelphia EZ Only}

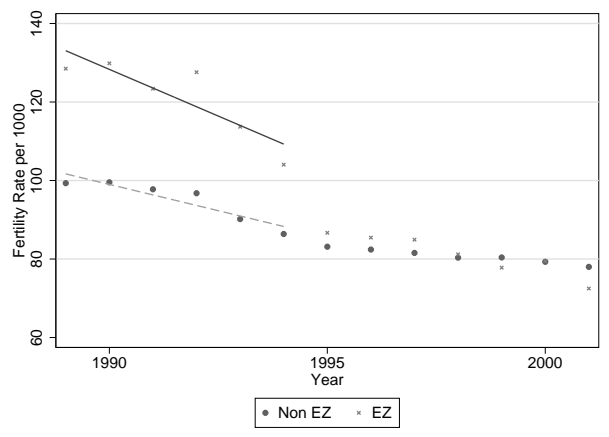

(a) Fertility

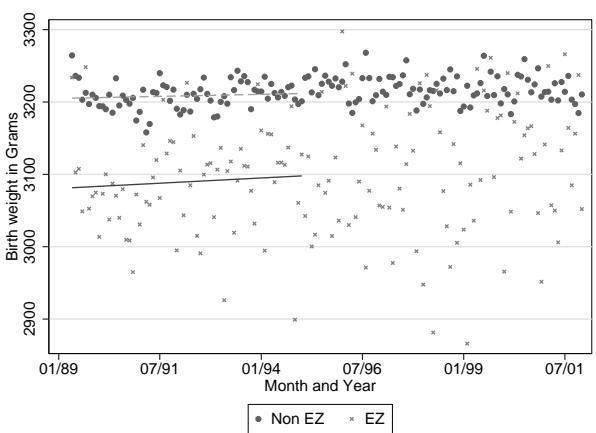

(b) Birth Weight

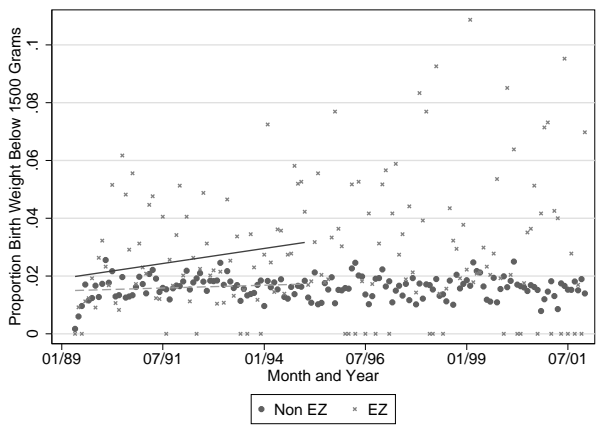

(d) Very Low Birth Weight

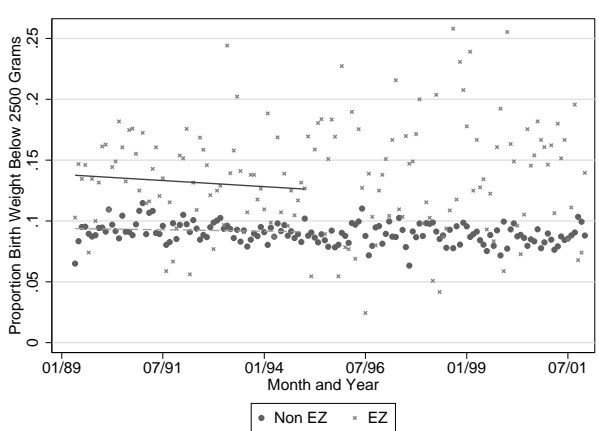

(c) Low Birth Weight

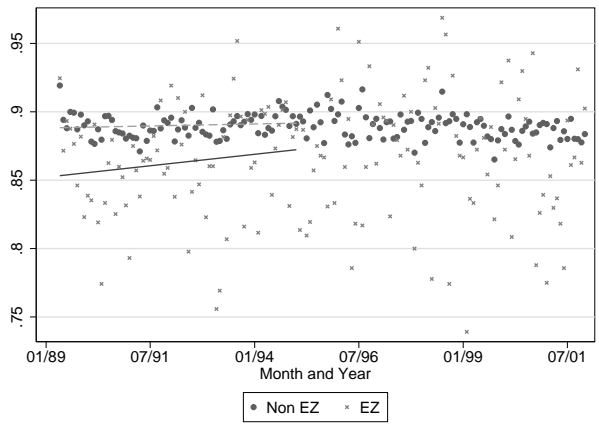

(e) Full-term

Source: Fertility and birth outcomes collapsed by year or month, with linear trend lines for both the pre- and post- empowerment zone periods. Philadelphia EZ compared to the limited sample of controls (Busso et al. 2013), excluding controls from cities with populations less than 100,000 or with less than 10 census tracts in the original application zone. 


\section{Figure A4: The Effect of Empowerment Zone Status on Birth Weight Using Synthetic Control Methods}

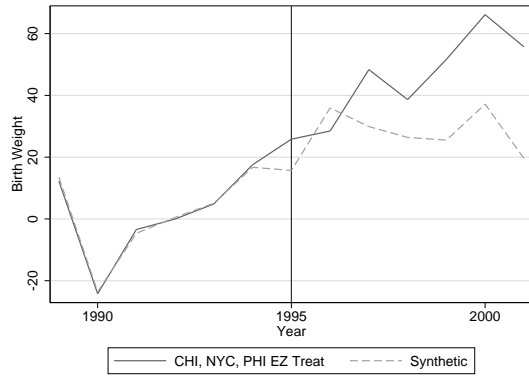

(a) EZ estimate

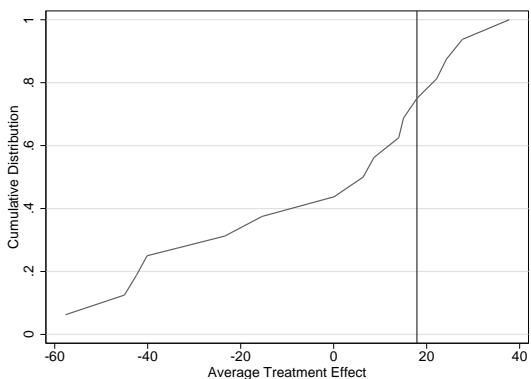

(c) Average Treatment Effect

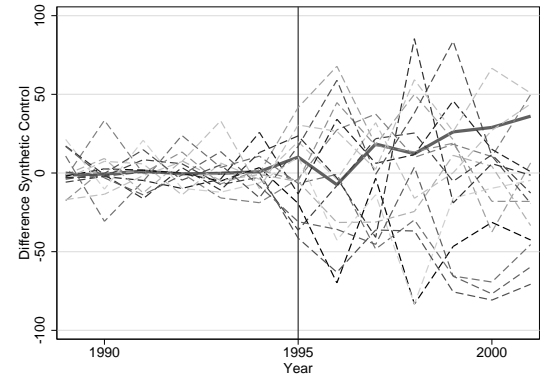

(b) Inference

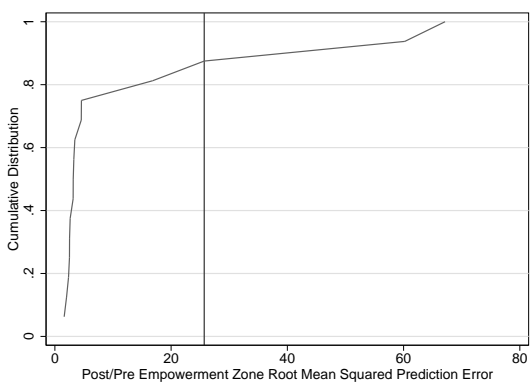

(d) Root Mean Sqared Error

Source: Author's estimation of equation (2) in the text, using the full sample of EZs and the limited sample of controls (Busso et al. 2013), excluding controls from cities with populations less than 100,000 or with less than 10 census tracts in the original application zone. Panel (a) provides estimates of the synthetic control method using EZ as the treatment. Panel (b) provides estimates of the effect of EZ status, systematically assigning EZ status to the actual EZ (the solid line) and all control zones (the dotted lines). Panel (c) provides the cumulative distribution of average treatment effects using estimates from the full inference sample, with a vertical line showing the average treatment effect for the actual EZ. Panel $(\mathrm{d})$ provides the cumulative distribution of the ratio of post- to pre-root mean squared prediction error for the full inference sample, with a vertical line showing the value for the actual EZ. 
Figure A5: The Effect of Empowerment Zone Status on Low Birth Weight Using Synthetic Control Methods

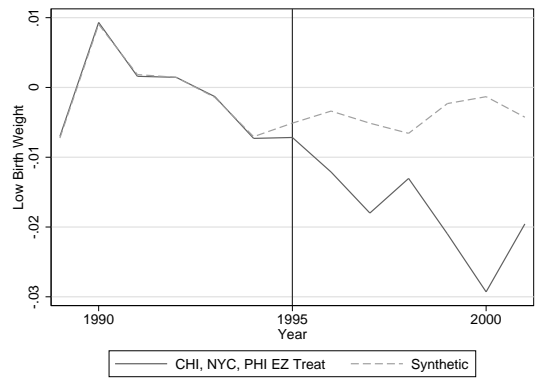

(a) EZ estimate

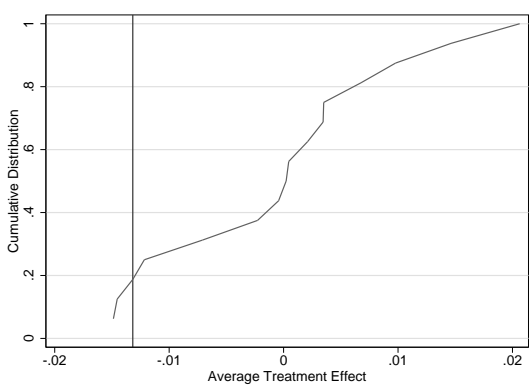

(c) Average Treatment Effect

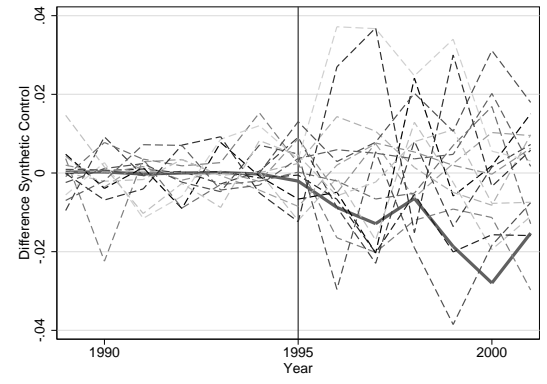

(b) Inference

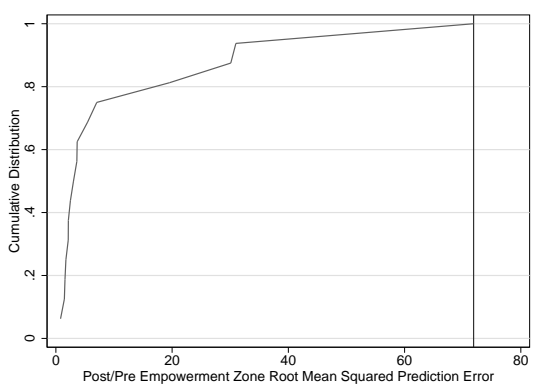

(d) Root Mean Sqared Error

Source: Author's estimation of equation (2) in the text, using the full sample of EZs and the limited sample of controls (Busso et al. 2013), excluding controls from cities with populations less than 100,000 or with less than 10 census tracts in the original application zone. Panel (a) provides estimates of the synthetic control method using EZ as the treatment. Panel (b) provides estimates of the effect of EZ status, systematically assigning EZ status to the actual EZ (the solid line) and all control zones (the dotted lines). Panel (c) provides the cumulative distribution of average treatment effects using estimates from the full inference sample, with a vertical line showing the average treatment effect for the actual EZ. Panel (d) provides the cumulative distribution of the ratio of post- to pre-root mean squared prediction error for the full inference sample, with a vertical line showing the value for the actual EZ. 
Figure A6: The Effect of Empowerment Zone Status on Very Low Birth Weight Using Synthetic Control Methods

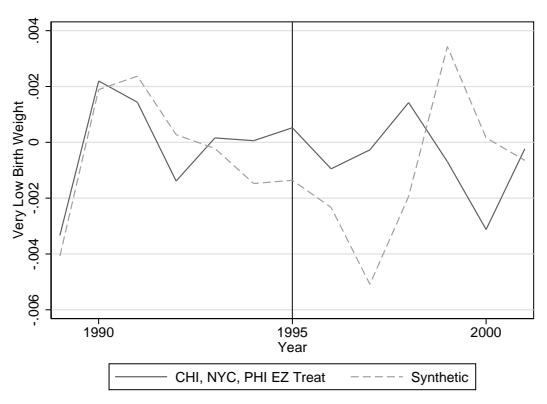

(a) EZ estimate

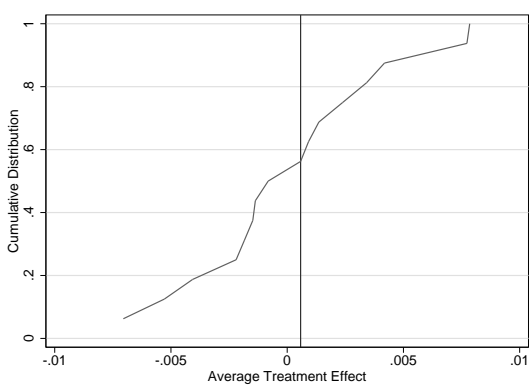

(c) Average Treatment Effect

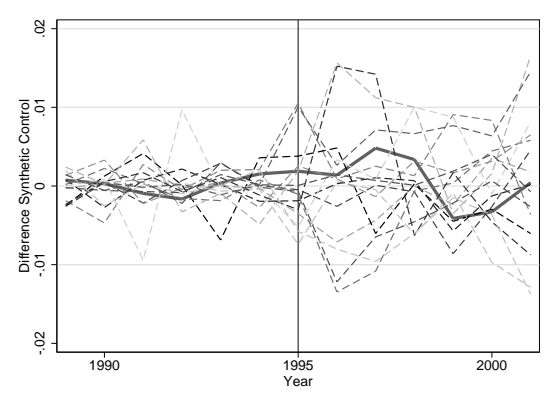

(b) Inference

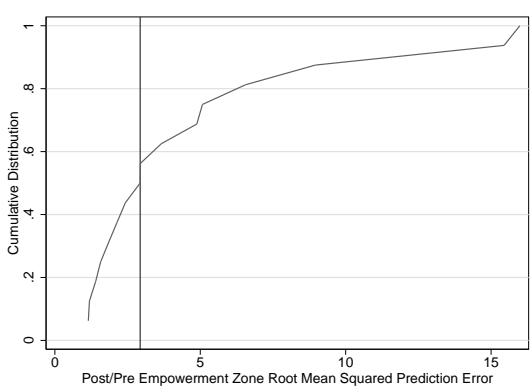

(d) Root Mean Sqared Error

Source: Author's estimation of equation (2) in the text, using the full sample of EZs and the limited sample of controls (Busso et al. 2013), excluding controls from cities with populations less than 100,000 or with less than 10 census tracts in the original application zone. Panel (a) provides estimates of the synthetic control method using EZ as the treatment. Panel (b) provides estimates of the effect of EZ status, systematically assigning EZ status to the actual EZ (the solid line) and all control zones (the dotted lines). Panel (c) provides the cumulative distribution of average treatment effects using estimates from the full inference sample, with a vertical line showing the average treatment effect for the actual EZ. Panel (d) provides the cumulative distribution of the ratio of post- to pre-root mean squared prediction error for the full inference sample, with a vertical line showing the value for the actual EZ. 
Figure A7: The Effect of Empowerment Zone Status on Gestational Age Using Synthetic Control Methods

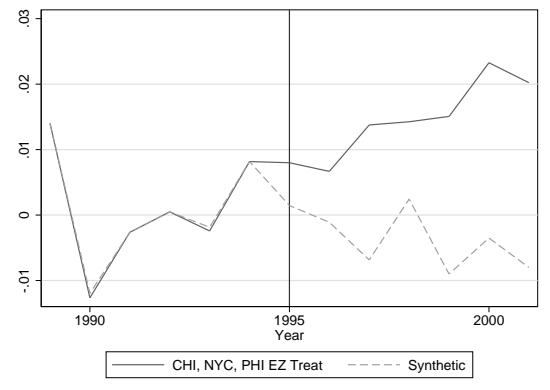

(a) EZ estimate

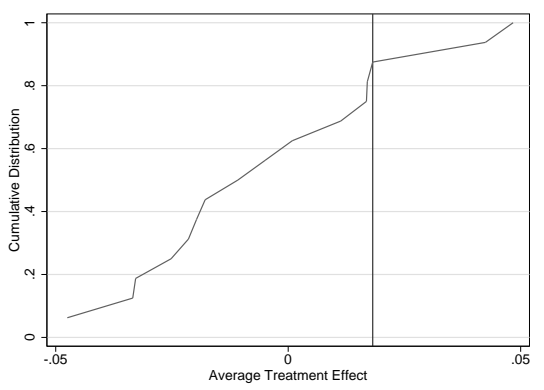

(c) Average Treatment Effect

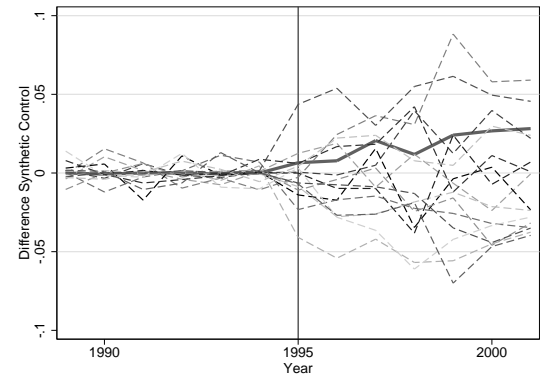

(b) Inference

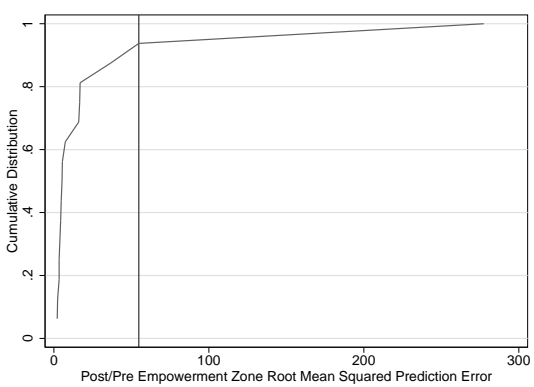

(d) Root Mean Sqared Error

Source: Author's estimation of equation (2) in the text, using the full sample of EZs and the limited sample of controls (Busso et al. 2013), excluding controls from cities with populations less than 100,000 or with less than 10 census tracts in the original application zone. Panel (a) provides estimates of the synthetic control method using EZ as the treatment. Panel (b) provides estimates of the effect of EZ status, systematically assigning EZ status to the actual EZ (the solid line) and all control zones (the dotted lines). Panel (c) provides the cumulative distribution of average treatment effects using estimates from the full inference sample, with a vertical line showing the average treatment effect for the actual EZ. Panel $(\mathrm{d})$ provides the cumulative distribution of the ratio of post- to pre-root mean squared prediction error for the full inference sample, with a vertical line showing the value for the actual EZ. 
Figure A8: The Effect of Empowerment Zone Status on Birth Weight by Quantile

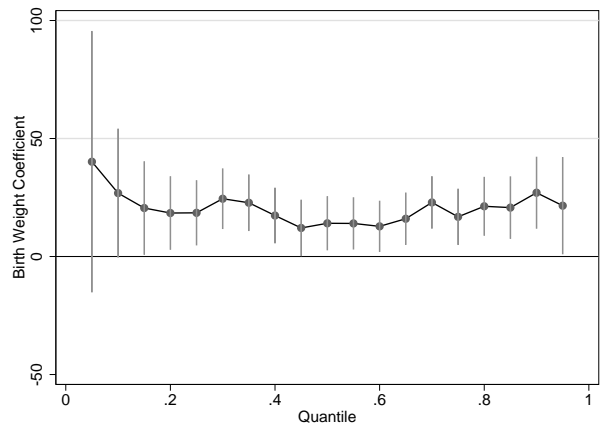

(a) Chicago

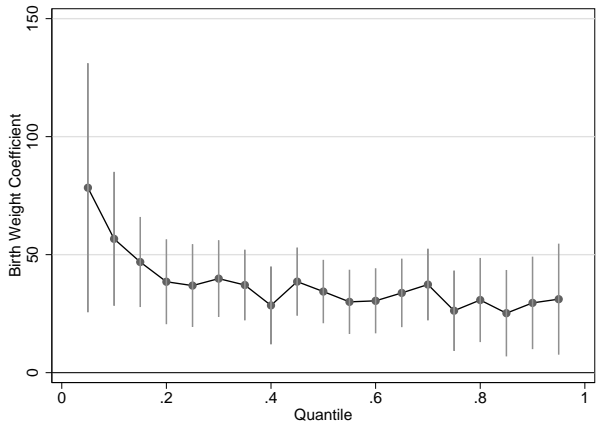

(b) New York

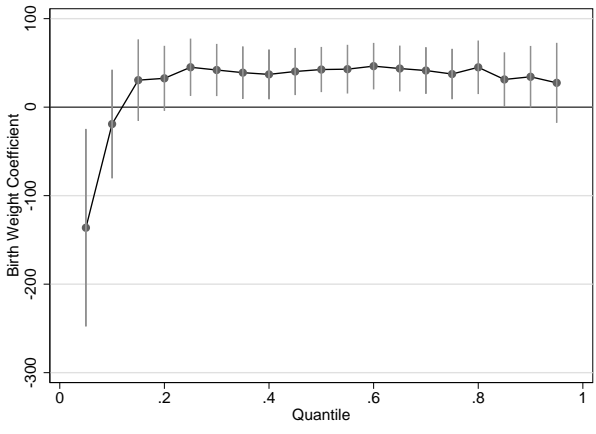

(c) Philadelphia

Source: These figures present results of separate unconditional quantile regressions (Firpo et al. 2009) for every fifth percentile of the birth weight distribution. The sample of EZs used in each panel is listed below the figures. Each panel uses the limited sample of controls (Busso et al. 2013), excluding controls from cities with populations less than 100,000 or with less than 10 census tracts in the original application zone. 


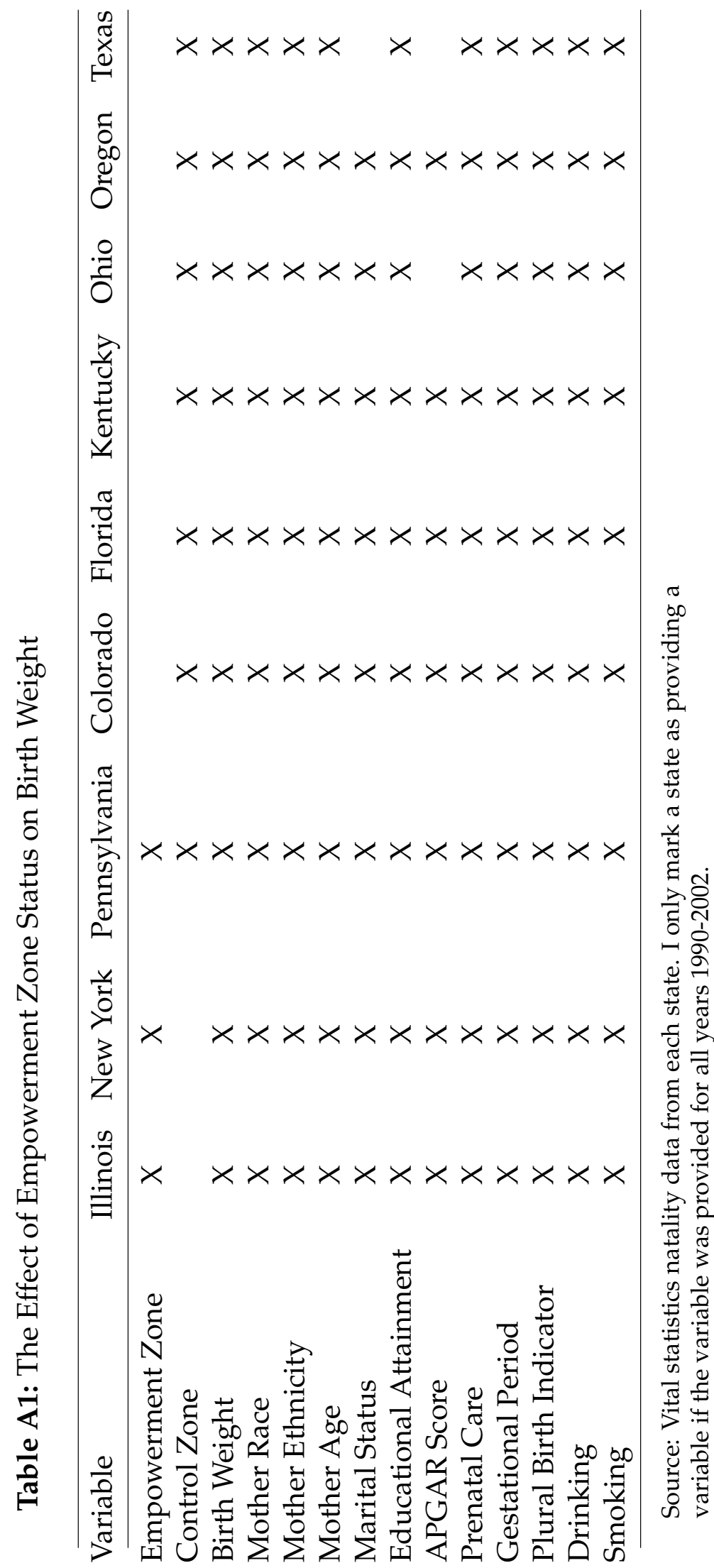


Table A2: Empowerment Zones and Control Areas Used in this Study

\begin{tabular}{|c|c|c|}
\hline Program Name & Treatment & Limited Sample \\
\hline Austin, TX & & $X$ \\
\hline \multicolumn{3}{|l|}{ Bellmead/Waco, TX } \\
\hline \multicolumn{3}{|l|}{ Chester, PA } \\
\hline Chicago, IL & $X$ & \\
\hline Cincinnati, $\mathrm{OH}$ & & $\mathrm{X}$ \\
\hline \multicolumn{3}{|l|}{ Cleveland, $\mathrm{OH}$} \\
\hline Columbus, $\mathrm{OH}$ & & $X$ \\
\hline Corpus Christi, TX & & $X$ \\
\hline Dallas, TX & & $X$ \\
\hline \multicolumn{3}{|l|}{ Dauphin, PA } \\
\hline Denver, $\mathrm{CO}$ & & $X$ \\
\hline El Paso, TX & & $X$ \\
\hline \multicolumn{3}{|l|}{ Fort Lauderdale, FL } \\
\hline \multicolumn{3}{|l|}{ Fort Worth, TX } \\
\hline \multicolumn{3}{|l|}{ Greeley/Evans, CO } \\
\hline Houston, TX & & $X$ \\
\hline Jacksonville, FL & & $X$ \\
\hline Louisville, KY & & $\mathrm{X}$ \\
\hline Miami, FL & & $\mathrm{X}$ \\
\hline New York City, NY & $X$ & \\
\hline Philadelphia, PA & $X$ & \\
\hline Pittsburgh, PA & & $X$ \\
\hline \multicolumn{3}{|l|}{ Port Arthur, TX } \\
\hline Portland, OR & & $X$ \\
\hline San Antonio, TX & & $X$ \\
\hline Summit, $\mathrm{OH}$ & & $X$ \\
\hline Tampa, FL & & $X$ \\
\hline
\end{tabular}

Source: Data are from vital statistics data from Colorado, Florida, Illinois, Kentucky, New York, Ohio, Oregon, Pennsylvania, and Texas. The limited sample of controls excludes controls from cities with populations less than 100,000 or with less than 10 census tracts in the original application zone (Busso et al. 2013). 
Table A3: The Effect of Empowerment Zone Status on Predicted Birth Outcomes Using 1990-1994 Data to Predict Outcomes Using Same City Control Areas

\begin{tabular}{|c|c|c|c|c|c|}
\hline & $\begin{array}{c}\text { Fertility } \\
\text { per } \\
1,000\end{array}$ & $\begin{array}{c}\text { Birth } \\
\text { Weight } \\
\text { (Grams) }\end{array}$ & $\begin{array}{c}\text { Low } \\
\text { Birth } \\
\text { Weight }\end{array}$ & $\begin{array}{c}\text { Very Low } \\
\text { Birth } \\
\text { Weight }\end{array}$ & $\begin{array}{c}\text { Full-term } \\
37+ \\
\text { Weeks }\end{array}$ \\
\hline \multicolumn{6}{|c|}{ Panel A. Chicago, New York, and Philadelphia Zone Compared } \\
\hline \multirow[b]{2}{*}{ Predicted } & to Contr & Zones & & & \\
\hline & $\begin{array}{c}1.253 \\
(1.380)\end{array}$ & $\begin{array}{c}2.022 \\
(2.690)\end{array}$ & $\begin{array}{c}0.000 \\
(0.001)\end{array}$ & $\begin{array}{c}0.0001 \\
(0.0001)\end{array}$ & $\begin{array}{c}-0.0002 \\
(0.0008)\end{array}$ \\
\hline \multicolumn{6}{|c|}{ Panel B. Only Chicago Zone Compared to Control Zones } \\
\hline Predicted & $\begin{array}{c}3.415^{* * *} \\
(0.715)\end{array}$ & $\begin{array}{c}0.360 \\
(4.956)\end{array}$ & $\begin{array}{c}-0.0003 \\
(0.002)\end{array}$ & $\begin{array}{c}-0.00003 \\
(0.0003)\end{array}$ & $\begin{array}{l}0.0002 \\
(0.001)\end{array}$ \\
\hline \multicolumn{6}{|c|}{ Panel C. Only New York Zone Compared to Control Zones } \\
\hline Predicted & $\begin{array}{c}0.747 \\
(0.713)\end{array}$ & $\begin{array}{c}1.330 \\
(1.856)\end{array}$ & $\begin{array}{c}0.0005 \\
(0.0007)\end{array}$ & $\begin{array}{c}0.0002 \\
(0.0002)\end{array}$ & $\begin{array}{c}-0.0008 \\
(0.0007)\end{array}$ \\
\hline \multicolumn{6}{|c|}{ Panel D. Only Philadelphia Zone Compared to Control Zonє } \\
\hline redicted & $\begin{array}{l}-0.950 \\
(0.895)\end{array}$ & $\begin{array}{c}12.07^{* * *} \\
(4.497)\end{array}$ & $\begin{array}{c}-0.003^{* *} \\
(0.001)\end{array}$ & $\begin{array}{c}-0.0005^{* *} \\
(0.0002)\end{array}$ & $\begin{array}{c}0.003^{* * *} \\
(0.001)\end{array}$ \\
\hline
\end{tabular}

Source: Author's estimation using predicted values of fertility rates calculated using demographically weighted 1990 national age-race fertility rates. Predicted values of birth outcomes calculated by regressing birth outcome on maternal demographic characteristics including race and ethnicity, educational attainment, and mothers age at the time of birth for 1989-1994. Predicted estimates come from regressing predicted outcomes on an indicator variable for whether the birth occurred in an EZ, the interaction of the variable EZ and post, an indicator for whether the baby was conceived in 1995 or later, and year fixed effects which subsume the variable post. I use all EZs and a control group composed of babies born to mothers living in census tracts in the same city as EZs with poverty rates above $20 \%$. Standard errors clustered at the program level are in parentheses: ${ }^{* * *}$ indicates significance at the $1 \%$ level, ${ }^{* *}$ indicates significance at the $5 \%$ level, ${ }^{*}$ indicates significance at the $10 \%$ level. 
Table A4: The Effect of Empowerment Zone Status on Birth Weight Matched on Trend and Level: Synthetic Control Inference Results

\begin{tabular}{cccccc}
\hline & $\begin{array}{c}\text { Fertility } \\
\text { per }\end{array}$ & $\begin{array}{c}\text { Birth } \\
\text { Weight }\end{array}$ & $\begin{array}{c}\text { Low } \\
\text { Birth }\end{array}$ & $\begin{array}{c}\text { Very Low } \\
\text { Birth }\end{array}$ & $\begin{array}{c}\text { Full-term } \\
37+\end{array}$ \\
& 1,000 & (Grams) & Weight & Weight & Weeks \\
\hline All EZs & -13.050 & $23.700^{+}$ & -0.011 & -0.001 & $0.003^{+}$ \\
& $(0.125)$ & $(0.250)$ & $(0.188)$ & $(0.500$ & $(0.625)$ \\
& $(0.750)$ & $(0.063)$ & $(0.125)$ & $(0.625)$ & $(0.063)$ \\
\hline
\end{tabular}

Source: Author's estimation of equation (2) in the text using the empowerment zones listed in the column and limited sample of controls (Busso et al. 2013), excluding controls from cities with populations less than 100,000 or with less than 10 census tracts in the original application zone. Data are from vital statistics data from Colorado, Florida, Illinois, Kentucky, New York, Ohio, Oregon, Pennsylvania, and Texas. The analysis sample is composed of babies born to mothers living in empowerment zones or control areas, which are areas that applied for, but did receive, empowerment zone status or areas that received empowerment zone status in a later round. The sample consists of 3 empowerment zones and 16 control zones. Each cell represents the average treatment effect from a separate synthetic control estimate. The numbers in parentheses in row 2 represent the implied $p$ value of the average treatment effect (ATE). The numbers in parentheses in row 3 represents the implied $p$ value of the ratio of the post to pre root mean squared prediction error (MSPE). ${ }^{*}$ indicates significance at the $10 \%$ level using ATE, + indicates significance at the $10 \%$ level using MSPE. The estimates include controls for child's gender, mother's race and ethnicity, tract level demographic characteristics including race and ethnicity, educational attainment, median household income, vacancy rates, and poverty rates. All outcome, individual and tract level demographic characteristics are aggregated up to the program level. 
Table A5: The Effect of Empowerment Zone Status on Birth Weight, Using Year of Birth

\begin{tabular}{|c|c|c|c|c|c|}
\hline & $\begin{array}{c}\text { Fertility } \\
\text { per } 1,000\end{array}$ & $\begin{array}{c}\text { Birth } \\
\text { Weight } \\
\text { in Grams }\end{array}$ & $\begin{array}{c}\text { Low } \\
\text { Birth } \\
\text { Weight } \\
\end{array}$ & $\begin{array}{c}\text { Very Low } \\
\text { Birth } \\
\text { Weight }\end{array}$ & $\begin{array}{c}\text { Full-term } \\
37+ \\
\text { Weeks } \\
\end{array}$ \\
\hline \multicolumn{6}{|c|}{ Panel A. Difference-in-Differences using Cross City Controls } \\
\hline $\begin{array}{l}\text { Difference-in- } \\
\text { Differences }\end{array}$ & $\begin{array}{c}-9.570^{* * *} \\
(2.832)\end{array}$ & $\begin{array}{c}27.058^{* * *} \\
(8.611)\end{array}$ & $\begin{array}{c}-0.009^{* * *} \\
(0.003)\end{array}$ & $\begin{array}{c}0.000 \\
(0.001)\end{array}$ & $\begin{array}{l}0.009^{* *} \\
(0.004)\end{array}$ \\
\hline Obs & & 366 & 3665 & 366501 & 360419 \\
\hline Dep Var Mean & 88.100 & 3197.203 & 0.098 & 0.017 & 0.885 \\
\hline \multicolumn{6}{|c|}{ Panel B. Synthetic Controls Matched on Trend } \\
\hline $\begin{array}{l}\text { Synthetic } \\
\text { Controls }\end{array}$ & $\begin{array}{l}-12.429 \\
(0.188) \\
(0.188)\end{array}$ & $\begin{array}{c}51.809^{+} \\
(0.125) \\
(0.000)\end{array}$ & $\begin{array}{c}-0.018^{*+} \\
(0.063) \\
(0.000)\end{array}$ & $\begin{array}{c}0.001 \\
(0.688) \\
(0.188)\end{array}$ & $\begin{array}{l}0.001^{+} \\
(0.625) \\
(0.000)\end{array}$ \\
\hline \multicolumn{6}{|c|}{ Panel C. Synthetic Controls Matched on Level and Trend } \\
\hline $\begin{array}{l}\text { Synthetic } \\
\text { Controls }\end{array}$ & & $\begin{array}{l}12.524 \\
(0.375) \\
(0.438)\end{array}$ & $\begin{array}{c}-0.013^{+} \\
(0.250) \\
(0.000)\end{array}$ & $\begin{array}{l}-0.001^{+} \\
(0.500) \\
(0.063)\end{array}$ & $\begin{array}{c}0.003 \\
(0.563) \\
(0.125)\end{array}$ \\
\hline
\end{tabular}

Source: Author's estimation of equation (1) and (2) in the text using the empowerment zones listed in the panel and controls. Data are from vital statistics data from Colorado, Florida, Illinois, Kentucky, New York, Ohio, Oregon, Pennsylvania, and Texas. The analysis sample is composed of babies born to mothers living in empowerment zones or control areas, which are areas that applied for, but did receive, empowerment zone status or areas that received empowerment zone status in a later round. Panel $\mathrm{B}$ estimates equation (2) matched on the trend of the dependent variable. Panel C estimates equation (2) matched on the trend and level of the dependent variable. Each cell in the table comes from a separate regression. The estimates include controls for mother's race and ethnicity, child's gender, and year fixed effects, controls for tract level demographic characteristics including race and ethnicity, educational attainment, median household income, vacancy rates, and poverty rates, and tract level fixed effects. Fertility rate regressions are performed at the aggregated EZ program level. Standard errors clustered at the program level are in parentheses: *** indicates significance at the $1 \%$ level, ${ }^{* *}$ indicates significance at the $5 \%$ level, * indicates significance at the $10 \%$ level. The numbers in parentheses for synthetic controls represent the implied $p$ value of the average treatment effect (ATE), and the implied $p$ value of the ratio of the post to pre root mean squared prediction error (MSPE). * indicates significance at the $10 \%$ level using ATE, + indicates significance at the $10 \%$ level using MSPE. 
Table A6: The Effect of Empowerment Zone Status on Birth Weight, Using the Full Set of Controls

\begin{tabular}{cccccc}
\hline & \multicolumn{1}{c}{$\begin{array}{c}\text { Birth } \\
\text { Fertility } \\
\text { per 1,000 }\end{array}$} & $\begin{array}{c}\text { Weight } \\
\text { in Grams }\end{array}$ & $\begin{array}{c}\text { Bow } \\
\text { Weight }\end{array}$ & $\begin{array}{c}\text { Very Low } \\
\text { Birth } \\
\text { Weight }\end{array}$ & $\begin{array}{c}\text { Full-term } \\
37+ \\
\text { Weeks }\end{array}$ \\
\hline Panel A. Using Year of Conception \\
(1) Difference-in- & $-12.559^{* * *}$ & $23.834^{* * *}$ & $-0.008^{* * *}$ & 0.001 & $0.010^{* *}$ \\
Differences & $(3.589)$ & $(7.424)$ & $(0.003)$ & $(0.001)$ & $(0.004)$ \\
Obs & 351 & 420560 & 420560 & 420560 & 414307 \\
Dep Var Mean & 95.434 & 3185.318 & 0.102 & 0.018 & 0.885 \\
\hline (2) Synthetic & $-13.387^{*+}$ & $28.222^{*}$ & -0.012 & 0.000 & $0.011^{+}$ \\
Controls & $(0.042)$ & $(0.042)$ & $(0.167)$ & $(0.625)$ & $(0.792)$ \\
& $(0.000)$ & $(0.125)$ & $(0.125)$ & $(0.333)$ & $(0.083)$ \\
\hline Panel B. Using Year of Birth & & & & \\
(3) Difference-in- & $-11.574^{* * *}$ & $24.014^{* * *}$ & $-0.009^{* * *}$ & 0.001 & $0.010^{* *}$ \\
Differences & $(3.840)$ & $(7.988)$ & $(0.003)$ & $(0.001)$ & $(0.004)$ \\
Obs & 324 & 427587 & 427587 & 427587 & 421300 \\
Dep Var Mean & 85.235 & 3195.600 & 0.098 & 0.018 & 0.886 \\
\hline (4) Synthetic & $-26.152^{*+}$ & $33.925^{+}$ & $-0.013^{+}$ & 0.001 & $0.016^{+}$ \\
Controls & $(0.042)$ & $(0.125)$ & $(0.167)$ & $(0.583)$ & $(0.750)$ \\
& $(0.042)$ & $(0.000)$ & $(0.042)$ & $(0.375)$ & $(0.000)$ \\
\hline
\end{tabular}

Source: Author's estimation of equation (1) in the text using the empowerment zones listed in the panel and the full sample of controls. Data are from vital statistics data from Colorado, Florida, Illinois, Kentucky, New York, Ohio, Oregon, Pennsylvania, and Texas. The analysis sample is composed of babies born to mothers living in empowerment zones or control areas, which are areas that applied for, but did receive, empowerment zone status or areas that received empowerment zone status in a later round. The sample consists of 3 empowerment zones and 24 control zones. Each cell in the table comes from a separate regression. The estimates include controls for mother's age, race and ethnicity, child's gender, high school graduate, some college, and college graduate, and year fixed effects, controls for tract level demographic characteristics including race and ethnicity, educational attainment, median household income, vacancy rates, and poverty rates, and tract level fixed effects. Fertility rate regressions are performed at the aggregated EZ program level. Standard errors clustered at the program level are in parentheses: $* * *$ indicates significance at the $1 \%$ level, ${ }^{* *}$ indicates significance at the $5 \%$ level, ${ }^{*}$ indicates significance at the $10 \%$ level. 
Table A7: The Effect of Empowerment Zone Status on Birth Weight: Chicago Results

\begin{tabular}{|c|c|c|c|c|c|}
\hline & $\begin{array}{c}\text { Fertility } \\
\text { per } \\
1,000\end{array}$ & $\begin{array}{c}\text { Birth } \\
\text { Weight } \\
\text { (Grams) }\end{array}$ & $\begin{array}{c}\text { Low } \\
\text { Birth } \\
\text { Weight }\end{array}$ & $\begin{array}{l}\text { Very Low } \\
\text { Birth } \\
\text { Weight }\end{array}$ & $\begin{array}{c}\text { Full-term } \\
37+ \\
\text { Weeks }\end{array}$ \\
\hline \multicolumn{6}{|c|}{ Panel A. Only Chicago Zone Compared to Cross City Control Areas } \\
\hline (1) Difference-in- & $-13.2^{* * *}$ & $18.1^{* * *}$ & $-0.007^{* * *}$ & 0.001 & 0.005 \\
\hline \multirow{2}{*}{ Obs Differences } & $(2.145)$ & (6.368) & $(0.002)$ & $(0.001)$ & $(0.004)$ \\
\hline & 208 & 298963 & 298963 & 298963 & 293550 \\
\hline Dep Var Mean & 88.9 & 3202.1 & 0.095 & 0.017 & 0.886 \\
\hline \multirow{3}{*}{$\begin{array}{l}\text { (2) Synthetic } \\
\text { Controls }\end{array}$} & $-21.7^{*+}$ & $8.7^{+}$ & -0.0120 & 0.001 & $0.012^{+}$ \\
\hline & $(0.063)$ & $(0.375)$ & $(0.250)$ & $(0.625)$ & $(0.750)$ \\
\hline & $(0.063)$ & $(0.000)$ & $(0.125)$ & $(0.563)$ & $(0.063)$ \\
\hline \multicolumn{6}{|c|}{ Panel B. Only Chicago Zone Compared to Same City Control Areas } \\
\hline (3) Difference-in- & $-12.4^{* * *}$ & $16.1^{* * *}$ & $-0.006^{* * *}$ & -0.001 & $0.004^{*}$ \\
\hline \multirow{2}{*}{ Obs Differences } & $(3.245)$ & $(5.676)$ & $(0.002)$ & $(0.001)$ & $(0.002)$ \\
\hline & 377 & 203937 & 203937 & 203937 & 200794 \\
\hline Dep Var Mean & 79.5 & 3174.7 & 0.107 & 0.020 & 0.882 \\
\hline \multirow{3}{*}{$\begin{array}{l}\text { (4) Synthetic } \\
\text { Controls }\end{array}$} & $-16.5^{+}$ & 26.8 & $-0.015^{+}$ & -0.001 & $0.004^{+}$ \\
\hline & $(0.200)$ & $(0.250)$ & $(0.150)$ & $(0.526)$ & $(0.650)$ \\
\hline & $(0.000)$ & (0.100) & $(0.000)$ & $(0.211)$ & $(0.000)$ \\
\hline
\end{tabular}

Source: Author's estimation of equations (1) and (2) in the text using the Chicago empowerment zone and control zones listed in the panel. Data are from vital statistics data from Colorado, Florida, Illinois, Kentucky, Ohio, Oregon, Pennsylvania, and Texas. In Panel A, the analysis sample is composed of babies born to mothers living in the Chicago EZ or control areas, which are areas that applied for, but did receive, empowerment zone status or areas that received empowerment zone status in a later round. Panel B uses a control sample of babies born to mothers living in census tracts in Chicago with poverty rates above $20 \%$. Each cell in the table comes from a separate regression. The estimates include controls for mother's race and ethnicity, child's gender, and year fixed effects, controls for tract level demographic characteristics including race and ethnicity, educational attainment, median household income, vacancy rates, and poverty rates, and tract level fixed effects. Fertility rate regressions are performed at the aggregated EZ program level. Standard errors clustered at the program level are in parentheses: ${ }^{* *}$ indicates significance at the $1 \%$ level, ${ }^{* *}$ indicates significance at the 5\% level, ${ }^{*}$ indicates significance at the $10 \%$ level. The numbers in parentheses for synthetic controls represent the implied $p$ value of the average treatment effect (ATE). The numbers in parentheses the next row represent the implied $\mathrm{p}$ value of the ratio of the post to pre root mean squared prediction error (MSPE). * indicates significance at the 10\% level using ATE, + indicates significance at the $10 \%$ level using MSPE. 
Table A8: The Effect of Empowerment Zone Status on Birth Weight: New York Results

\begin{tabular}{cccccc}
\hline & $\begin{array}{c}\text { Birth } \\
\text { Fertility } \\
\text { per 1,000 }\end{array}$ & $\begin{array}{c}\text { Weight } \\
\text { in Grams }\end{array}$ & $\begin{array}{c}\text { Low } \\
\text { Birth } \\
\text { Weight }\end{array}$ & $\begin{array}{c}\text { Very Low } \\
\text { Birth } \\
\text { Weight }\end{array}$ & $\begin{array}{c}\text { Full-term } \\
37+ \\
\text { Weeks }\end{array}$ \\
\hline Panel A. Only New York Zone Compared to Cross City Control Areas \\
(1) Difference-in- & -4.1 & $42.6^{* * *}$ & $-0.015^{* * *}$ & -0.002 & $0.016^{* * *}$ \\
Differences & $(3.208)$ & $(6.589)$ & $(0.003)$ & $(0.001)$ & $(0.003)$ \\
Obs & 208 & 287105 & 287105 & 287105 & 282458 \\
Dep Var Mean & 87.1 & 3212.4 & 0.092 & 0.016 & 0.888 \\
\hline (2) Synthetic & $-4.6^{+}$ & $44.9^{*}$ & -0.018 & -0.004 & 0.030 \\
Controls & $(0.375)$ & $(0.000)$ & $(0.125)$ & $(0.125)$ & $(0.875)$ \\
& $(0.063)$ & $(0.313)$ & $(0.438)$ & $(0.375)$ & $(0.188)$ \\
\hline Panel B. Only New York Zone Compared to Same City Control Areas \\
(3) Difference-in- & $-6.4^{* *}$ & $27.5^{* * *}$ & $-0.012^{* * *}$ & 0.000 & $0.011^{* * *}$ \\
Differences & $(2.539)$ & $(3.851)$ & $(0.002)$ & $(0.001)$ & $(0.001)$ \\
Obs & 546 & 540209 & 540209 & 540209 & 530265 \\
Dep Var Mean & 69.8 & 3238.6 & 0.088 & 0.017 & 0.900 \\
\hline (4) Synthetic & -4.6 & 13.3 & -0.005 & $0.000^{+}$ & 0.012 \\
Controls & $(0.244)$ & $(0.317)$ & $(0.268)$ & $(0.439)$ & $(0.854)$ \\
& $(0.439)$ & $(0.415)$ & $(0.195)$ & $(0.049)$ & $(0.512)$ \\
\hline
\end{tabular}

Source: Author's estimation of equations (1) and (2) in the text using the New York empowerment zone and control zones listed in the panel. Data are from vital statistics data from Colorado, Florida, Kentucky, New York, Ohio, Oregon, Pennsylvania, and Texas. In Panel A, the analysis sample is composed of babies born to mothers living in the New York EZ or control areas, which are areas that applied for, but did receive, empowerment zone status or areas that received empowerment zone status in a later round. Panel B uses a control sample of babies born to mothers living in census tracts in Chicago with poverty rates above $20 \%$. Each cell in the table comes from a separate regression. The estimates include controls for mother's race and ethnicity, child's gender, and year fixed effects, controls for tract level demographic characteristics including race and ethnicity, educational attainment, median household income, vacancy rates, and poverty rates, and tract level fixed effects. Fertility rate regressions are performed at the aggregated EZ program level. Standard errors clustered at the program level are in parentheses: ${ }^{* * *}$ indicates significance at the $1 \%$ level, ${ }^{* *}$ indicates significance at the $5 \%$ level, ${ }^{*}$ indicates significance at the $10 \%$ level. The numbers in parentheses for synthetic controls represent the implied $p$ value of the average treatment effect (ATE). The numbers in parentheses the next row represent the implied $\mathrm{p}$ value of the ratio of the post to pre root mean squared prediction error (MSPE). ${ }^{*}$ indicates significance at the $10 \%$ level using ATE, + indicates significance at the $10 \%$ level using MSPE. 
Table A9: The Effect of Empowerment Zone Status on Birth Weight: Philadelphia Results

\begin{tabular}{|c|c|c|c|c|c|}
\hline & $\begin{array}{l}\text { Fertility } \\
\text { per } 1,000\end{array}$ & $\begin{array}{c}\text { Birth } \\
\text { Weight } \\
\text { in Grams }\end{array}$ & $\begin{array}{c}\text { Low } \\
\text { Birth } \\
\text { Weight }\end{array}$ & $\begin{array}{c}\text { Very Low } \\
\text { Birth } \\
\text { Weight }\end{array}$ & $\begin{array}{c}\text { Full-term } \\
37+ \\
\text { Weeks }\end{array}$ \\
\hline \multicolumn{6}{|c|}{ Panel A. Only Philadelphia Zone Compared to Cross City Control Areas } \\
\hline $\begin{array}{r}\text { (1) Difference-in- } \\
\text { Differences }\end{array}$ & & $\begin{array}{l}16.1^{* *} \\
(7.830)\end{array}$ & $\begin{array}{c}0.008^{* * *} \\
(0.003)\end{array}$ & $\begin{array}{l}0.009^{* * *} \\
(0.001)\end{array}$ & \\
\hline Obs & & 2 & & & 241431 \\
\hline Dep Var & & 321 & 0.0 & & 0.8 \\
\hline \multirow{3}{*}{$\begin{array}{l}\text { (2) Synthetic } \\
\text { Controls }\end{array}$} & $215 *$ & 28. & (n) & & $-0 .($ \\
\hline & & $(0.0$ & & $(0.9$ & 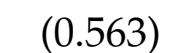 \\
\hline & & $(0.18$ & $(0.5$ & $(0.688)$ & $(0.188$ \\
\hline \multicolumn{6}{|c|}{ Panel B. Only Philadelphia Zone Compared to Same City Control Areas } \\
\hline \multirow{2}{*}{$\begin{array}{r}\text { (3) Difference-in- } \\
\text { Differences }\end{array}$} & $-14.5^{* * *}$ & 0.6 & $0.009^{* *}$ & $0.012^{* * *}$ & -0.003 \\
\hline & & & & & $(0.6$ \\
\hline Obs & & 105 & 105 & 105 & 104642 \\
\hline Dep Var Mean & 78.9 & 3130.5 & 0.121 & 0.023 & 0.865 \\
\hline \multirow{3}{*}{$\begin{array}{l}\text { (4) Synthetic } \\
\text { Controls }\end{array}$} & -14.4 & 6. & 0.0 & 0.0 & 0.0 \\
\hline & & & & & \\
\hline & & $(0.0$ & $(0.5$ & $(0.800)$ & $(0.500)$ \\
\hline
\end{tabular}

Source: Author's estimation of equations (1) and (2) in the text using the Philadelphia empowerment zone and control zones listed in the panel. Data are from vital statistics data from Colorado, Florida, Kentucky, Ohio, Oregon, Pennsylvania, and Texas. In Panel A, the analysis sample is composed of babies born to mothers living in the Philadelphia EZ or control areas, which are areas that applied for, but did receive, empowerment zone status or areas that received empowerment zone status in a later round. Panel B uses a control sample of babies born to mothers living in census tracts in Philadelphia with poverty rates above $20 \%$. Each cell in the table comes from a separate regression. The estimates include controls for mother's race and ethnicity, child's gender, and year fixed effects, controls for tract level demographic characteristics including race and ethnicity, educational attainment, median household income, vacancy rates, and poverty rates, and tract level fixed effects. Fertility rate regressions are performed at the aggregated EZ program level. Standard errors clustered at the program level are in parentheses: ${ }^{* * *}$ indicates significance at the $1 \%$ level, ${ }^{* *}$ indicates significance at the $5 \%$ level, ${ }^{*}$ indicates significance at the $10 \%$ level. The numbers in parentheses for synthetic controls represent the implied $p$ value of the average treatment effect (ATE). The numbers in parentheses the next row represent the implied $p$ value of the ratio of the post to pre root mean squared prediction error (MSPE). ${ }^{*}$ indicates significance at the $10 \%$ level using ATE, + indicates significance at the $10 \%$ level using MSPE. 